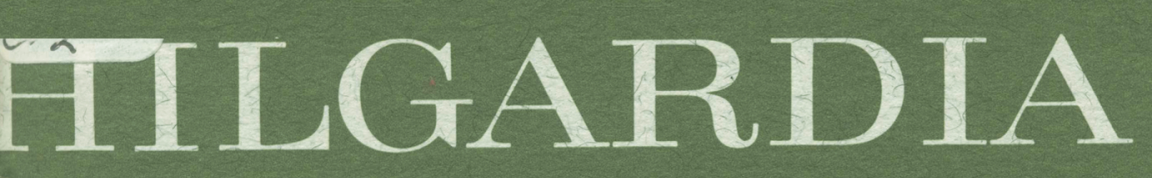

JOURNAL OF AGRICULTURAL SCIENCE PUBLISHED BY HE CALIFORNIA AGRICULTURALEXPERIMENT STATION

Volume 53• Number 2•June 1985

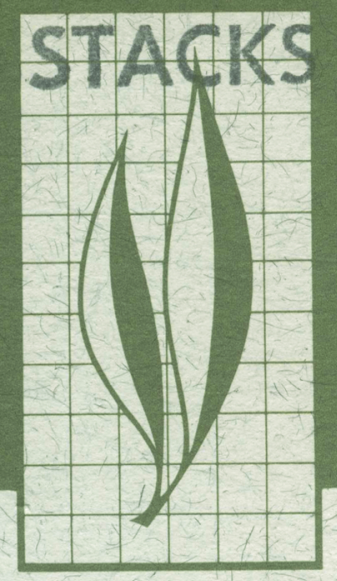

Biological Studies of Iceplant Scales,

Pulvinariella mesembryanthemi

and

\title{
Pulvinaria delottoi
}

\section{(Homoptera: Coccidae), in California}

Jan O. Washburn

and

Gordon W. Frankie 


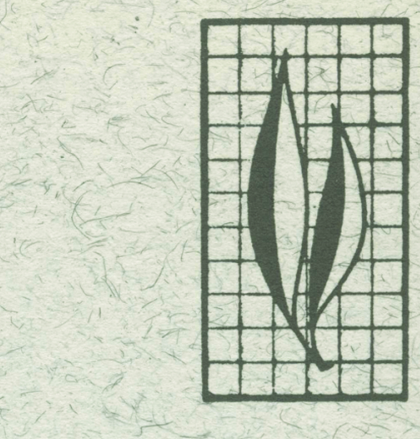

Two scale species native to southern Africa, Pulvinariella mesembryanthemi and Pulvinaria delottoi (Homoptera: Coccidae), were discovered in California in the vicinity of San Francisco Bay between 1971 and 1973. Laboratory host-range tests indicate that both species are polyphagous on species of Aizoaceae, but in California these scales feed primarily on cultivated and naturalized ornamentals in the genus Carpobrotus. Some succulents in the Crassulaceae are also suitable hosts.

Pulvinariella mesembryanthemi has spread rapidly throughout the coastal regions of the state, and its current geographical range extends from San Diego County in the south to Napa County in the north. The scale is also reported from Yolo and Sacramento counties in the Central Valley. Pulvinaria delottoi is presently restricted to counties surrounding San Francisco and Monterey bays, but it is likely to spread into all areas where $P$. mesembryantbemi occurs. The rapid spread of these scales has probably resulted from wind dispersal of the first instars.

Pulvinariella mesembryanthemi and $P$. delottoi are similar morphologically, but they differ in developmental time, selection of feeding sites by crawlers, and sex ratios. The developmental time of $P$. mesembryanthem $i$ is approximately half that of $P$. delotto $i$, and under field conditions north of Monterey County P. mesembryantbemi is bivoltine while $P$. delotto $i$ is univoltine. In Los Angeles and Orange counties, $P$. mesembryanthem $i$ has three generations per year, but when reared in warm greenhouse conditions this scale can complete a generation in 11 weeks. First instars of $P$. mesembryanthem $i$ preferentially settle on young iceplant leaves; $P$. delotto $i$ tends to settle on more mature leaves. This differential settling results in partial spatial segregation on host plants. Both species reproduce parthenogenetically, though males of $P$. mesembryantbem $i$ are commonly produced in low numbers. In both laboratory and field populations, sex ratios were always female biased, and matings were never observed. Although males of $\boldsymbol{P}$. delotto $i$ were produced very infrequently under laboratory conditions, they were never encountered in field populations.

\section{THE AUTHORS:}

Jan O. Washburn is a Postdoctoral Research Associate, Department of Entomology, and Gordon W. Frankie is Professor of Entomology, Department of Entomology, University of California, Berkeley. 


\section{Biological Studies of Iceplant Scales, Pulvinariella mesembryantbemi and Pulvinaria delottoi (Homoptera: Coccidae), in California ${ }^{1}$}

\section{INTRODUCTION}

The soft scale, Pulvinariella mesembryanthemi, was originally described by Vallot (1829) in the genus Pulvinaria (Homoptera: Coccoidea, Coccidae) from specimens collected on cultivated iceplants in southern France. The species is synonymous with Calypticus mesembryanthemi and Pulvinaria biplicata. Borchsenius (1953) moved P. mesembryantbemi to his newly erected genus Pulvinariella in which he included those Pulvinaria species with stout marginal setae. Pulvinaria delottoi was originally described (Gill 1979) from specimens collected in California and South Africa. Because this species is very similar to $P$. mesembryanthemi and possesses stout marginal setae, it should actually be placed in the genus Pulvinariella (Gill, personal communication). The two species differ in a few, minor morphological features, including shape and curvature of marginal setae, number of preopercular pores, and distribution of ventral microducts (Gill 1979).

Both $P$. mesembryanthemi and $P$. delottoi originated from South Africa where they live on host plants in the family Aizoaceae (Brain 1920; Gill 1979; DeLotto 1979). In South Africa and Ethiopia their primary host is Carpobrotus edulis (Hodgson 1967). Pulvinariella mesembryanthemi is also reported from southern Europe along the Mediterranean, the Canary Islands, Scilly Islands, Germany, Chile, Argentina, and Australia (Quintana 1956; DeLotto 1967; Hodgson 1967, 1968; Collins and Scott 1982). Dispersal of $P$. mesembryantbemi throughout the world has coincided with the spread of its South African hosts to areas with mild Mediterranean climates. At present, $P$. delotto $i$ is reported only from South Africa and California.

It is not known how $P$. mesembryanthemi arrived in North America, but in 1971 the first confirmed identification was made from specimens collected at two private residences in Napa, California. Pulvinaria delotto was discovered in Alameda County, California in 1973 on species of Crassula and Sedum (Crassulaceae) and Lampranthus (Aizoaceae) by J. Vettel and C. McGuire of the California Department of Agriculture. These iceplant scales rapidly assumed pest status in the state as they spread throughout the San Francisco Bay area. By 1977 dense populations of $P$. mesembryantbem $i$ were killing large landscaped areas of iceplants, Carpobrotus spp., that are widely used in California as ornamental ground covers. We initiated a study in 1978 funded by the California Department of Transportation (CALTRANS) to elucidate the natural histories, distribution, dispersal, and host-plant relations in California. Our goal was to elucidate biological information useful for development of a scale management program.

The potential economic impact of these scale pests in California is significant. CALTRANS, the single largest cultivator of aizoaceous ground covers in the state, maintains over 6,000 acres of iceplants along highways, and an equivalent acreage exists on private

${ }^{1}$ Accepted for publication January 9, 1985. 
and other lands (Donaldson et al. 1978). In addition to providing an aesthetically pleasing plant cover, iceplant landscapes serve as important deterrants to erosion in coastal and hillside settings. Interestingly, under some conditions iceplants are considered pest species. In many coastal plant communities of California (e.g., dunes, cliffs, and marshes) aggressive aizoaceous species have displaced native vegetation. In these instances iceplant scales have been considered for use as biological control agents to reduce iceplant populations.

In this paper we describe several aspects of the biologies of $P$. mesembryanthemi and $P$. delotto $i$ in California, including phenologies from different geographic areas within the state, laboratory studies of temperature-related population dynamics, settling behavior and plant tissue preferences of first instars (crawlers), and host-plant ranges.

\section{METHODS}

\section{Scale Phenology}

Between 1978 and 1983 field populations of $P$. mesembryanthemi and $P$. delottoi were sampled at sites from Napa to San Diego counties to determine generation times, growth rates, and reproductive characteristics (see table 1 and figure 3 for county distributions and field sites). Initially, between 1978 and 1980, P. mesembryanthemi populations from Napa, Napa County; Berkeley, Alameda County; and Danville Contra Costa County, were sampled every 2 weeks in spring and summer and every 4 weeks in fall and winter. Similar biweekly samples of $P$. mesembryanthemi were collected from San Francisco, San Francisco County, June 1981-February 1982; San Leandro, Alameda County, September 1981September 1982; Richmond, Contra Costa County, June 1980-July 1981; San Mateo, San Mateo County, September 1981-September 1982; and Sacramento, Sacramento and Yolo counties, June 1980-July 1982. Pulvinaria delottoi populations from Monterey, Monterey County; Berkeley, and Richmond were sampled on a similar schedule.

A sample consisted of 25 shoots, each supporting four or more scales. The lengths of 100 randomly selected, immature scales (four per shoot) were measured under magnification from each collection. During reproductive periods a random sample of 50 ovisacs was collected on each date and dissected to examine contents. Field notes were regularly taken on the presence of crawlers and occasional males.

By 1982 P. mesembryanthemi had spread south to Los Angeles, which led to sampling representative populations throughout the range of the scale along state highways on three dates at 4-month intervals over the course of a year. These collections provided information on how scale phenology and other biological characteristics varied geographically. A set of samples similar to those described above was collected at nine sites from Sacramento to Los Angeles in August 1982. When P. mesembryanthemi was first detected in San Diego in October 1982, three additional sites in San Diego County were added and sampled with the original nine in December 1982 and April 1983.

\section{Temperature-dependent growth and development}

Laboratory populations of both scale species were established from field-collected ovisacs and reared in constant temperature growth chambers with a 14-hour light cycle. For each species newly emerged crawlers (less than 24 hours old) were transferred with a fine camel hair brush to rooted cuttings of Carpobrotus edulis $\mathrm{x}$ aequalateris, the dominant iceplant 
TABLE 1. KNOWN COUNTY DISTRIBUTIONS OF P. MESEMBRYANTHEMI AND $P$. DELOTTOI IN CALIFORNIA

\begin{tabular}{lcc}
\hline \hline County & P. mesembryanthemi & P. delottoi \\
\hline Napa & 1971 & - \\
Alameda & 1973 & 1973 \\
Solano & 1974 & - \\
Contra Costa & 1978 & 1977 \\
Marin & 1978 & - \\
San Mateo & 1978 & 1975 \\
San Francisco & 1979 & - \\
Los Angeles & 1979 & - \\
Sacramento & 1979 & - \\
Yolo & 1979 & - \\
Monterey & 1980 & 1978 \\
Orange & 1980 & - \\
Santa Clara & 1980 & 1976 \\
Kern & $1981 *$ & - \\
Santa Barbara & 1981 & - \\
San Luis Obispo & 1981 & - \\
Ventura & 1981 & - \\
Santa Cruz & 1982 & 1973 \\
San Diego & 1982 & $1978 \dagger$ \\
Riverside & 1983 & - \\
Calaveras & 1983 & - \\
Sonoma & 1984 & - \\
San Joaquin & 1984 & - \\
Glenn & 1984 & - \\
\hline
\end{tabular}

*Population eradicated.

†On imported nursery stock, eradicated; dashes indicate absence of $P$. delotto $i$ in counties.

cultivar in California (W. Ferren, personal communication). All cuttings were approximately $25 \mathrm{~cm}$ long and derived from a single, small planting on the Berkeley campus of the University of California. Cuttings were planted in a soil mixture of 50 percent peat and 50 percent sand and allowed to root for 4 weeks prior to infestation with scales. The same source of plant material and potting method were used for all laboratory experiments. Each plant was infested with 100 crawlers, which were allowed to settle for 24 hours before the plants were transferred to growth chambers. Four plants were cultured for each scale species at five temperatures $\left(14.5^{\circ}, 17.0^{\circ}, 20.5^{\circ}, 24.5^{\circ}\right.$, and $\left.27^{\circ} \pm 1^{\circ} \mathrm{C}\right)$.

We measured growth rate, survivorship, and ovisac size for $P$. mesembryanthemi populations reared at each temperature. Populations of $P$. delottoi were maintained only through the second instar. Every 7 days for $P$. mesembryanthemi and every 14 days for $P$. delotto $i$ we measured to the nearest $0.5 \mathrm{~mm}$ the lengths of 45 scales on three plants (15 scales per plant) for each species and temperature. Initially we attempted to follow the development of individual scales, but as they grew some changed feeding sites, and it was not always possible to identify individuals. When this occurred, randomly chosen animals were measured to produce a sample size of 15 for each plant. Scales in the ovisac stage were not included in these samples.

As ovisacs of $P$. mesembryanthemi were produced they were excised from their hosts with a small piece of plant tissue and their lengths measured under a dissecting microscope to the nearest $0.01 \mathrm{~mm}$. Between 20 and 30 ovisacs were collected from scale populations reared in each temperature chamber. All ovisacs were secured individually in the center of paper discs bordered by Tanglefoot and were stored on enclosed racks in the greenhouse until all 
crawlers emerged. Emerging crawlers were intercepted by the Tanglefoot, and after emergence ceased the trapped individuals were counted. Additionally, we dissected each ovisac, counted the number of unemerged crawlers, and added these to the emerged crawlers to produce a fecundity value for each female. When the first crawlers in a temperature regime began to emerge, the total number of surviving scales was counted, and the plants and scales were discarded. Since $P$. delotto $i$ colonies were removed shortly after scales molted to the second instar, no fecundity values were determined.

\section{Crawler-settling behavior}

Two types of experiments were conducted to assess the settling behaviors of $P$. mesembryanthemi and $P$. delotto $i$ crawlers. In the first experiment we introduced newly emerged crawlers onto potted plants and allowed them to disperse and choose settling sites. For each scale species we introduced 100 crawlers onto each of seven potted Carpobrotus plants. After 1 week we carefully dissected each plant and examined all external leaf and stem surfaces for scales. For each leaf we recorded its length and the number of settled scales.

In the second experiment we tested the settling abilities, rather than the preferences, of crawlers of both species. Host plants were divided into three major types of potential settling sites that contain vascular elements: mature leaves, young leaves, and stems. In the mature category were included fully expanded and dark green leaves. Young leaves included the first one or two pairs of leaves on terminal shoots that were light green and not fully expanded. We cut ends from the smaller halves of gelatin capsules (Lilly No. 3) and secured the resulting cylinders to the plants with melted beeswax. A total of 600 gelatin cylinders was placed on 12 host plants; 100 pairs were attached to each of the three kinds of settling sites. Gelatin cylinders in pairs were adjacent to each other, and for each pair we added a crawler of $P$. mesembryanthemi to one of the cylinders and a crawler of $P$. delottoi to the other. We sealed each gelatin cylinder by sliding on the remaining half of the capsule, which prevented the crawler from escaping. Each crawler was thus forced to settle on the small circular area of available host tissue at the base of the cylinder if it was to survive. After 10 days we removed all gelatin capsules and counted the number of crawlers of each species that successfully settled on the different types of tissue. The experiment was replicated a second time and statistically evaluated (ANOVA).

\section{Scale feeding}

Coccid scales typically feed on the contents of phloem vessels, and the ability to use an individual leaf may be limited by accessibility to these vascular tissues. To determine the distribution and depth of Carpobrotus vascular bundles we made cross sections of leaves of varying lengths and examined them under magnification. We measured the distance from the outside surface of the epidermis to the network of xylem and phloem that is embedded in the lower levels of the mesophyll. By carefully cutting leaf tissues surrounding settled scales of different ages, we traced the feeding stylets to these bundles and identified this region as the major source of nutrition for second, third, and fourth instar scales. For each leaf we made cross sections in the basal, middle, and terminal thirds of the leaf and measured the distance to one vascular segment of the network on each of the three sides of the leaf. We calculated an average distance to the vascular network from the nine measurements per leaf and regressed these averages against the leaf lengths. 
We established the relationship between the size of feeding stylets and scale body length by measuring stylet lengths of all instars of $P$. mesembryanthem $i$ and $P$. delottoi. By carefully pulling scales perpendicularly from leaves we were able to withdraw the stylets intact from the plant. Stylet and body lengths for each scale were measured under magnification. Each stylet was extended across the surface of a glass slide until it was straight, and length from the tip to the junction with the body was measured. We omitted those scales having broken stylet tips. For each species we used least-squares linear regression to determine the relationship between stylet and body lengths.

\section{Host-plant ranges}

Cuttings of 50 plant species in the Aizoaceae and Crassulaceae were collected from specimens growing in the University of California Botanical Garden, Berkeley. From one to fifteen cuttings of each species were planted individually in small plastic pots and maintained in the greenhouse for a month prior to introduction of $P$. mesembryanthemi crawlers. Each plant was infested with 200-plus crawlers. Two weeks after crawler infestation we examined each plant for the presence of settlers. Plants lacking surviving settlers were reinfested with more crawlers and examined again after 2 weeks; if crawlers still failed to settle, the plant was considered unsuitable and discarded. We examined plants with settlers every 3 weeks until either ovisacs appeared or the scales died. Any plant species that successfully supported a scale population to the ovisac stage was considered an acceptable host. We repeated these procedures with $P$. delotto $i$ crawlers for some of the same plant species.

\section{Crawler behavior and emergence from ovisacs}

To determine the temporal emergence pattern of crawlers from ovisacs, we secured 20 ovisacs that contained eggs (but not crawlers) onto individual paper discs that were bordered with Tanglefoot. Ovisacs were maintained in a greenhouse, and each day they were moved between 1600 and 1700 hours to fresh discs; this procedure was continued until all crawlers had emerged. By counting the number of crawlers on each disc we were able to evaluate the daily emergence from each ovisac.

We examined the behavioral responses of $P$. mesembryanthemi and $P$. delotto $i$ crawlers to light and gravity. Gravity responses were tested by securing ovisacs on inclined discs bordered by Tanglefoot and examining the distribution of emerged crawlers trapped in the border. Discs were inclined at 5-degree intervals from zero to 90 degrees, and a single ovisac for each species was tested at each inclination. Discs were maintained in completely darkened boxes until all crawlers emerged. We divided the Tanglefoot border of each disc into 18 arcs of 20 degrees with the first arc extending 10 degrees on either side of the most elevated point on the disc, and we counted the total number of crawlers trapped in each arc.

Light responses were tested by brushing several hundred crawlers onto the center of a $30-\mathrm{cm}$ horizontal plexiglass bar divided into 10 segments of equal length. A small light source was focused above one randomly chosen segment, and the crawlers were allowed to move about for 30 minutes. At the end of this period we placed a piece of clear plastic tape along the entire length of the bar and counted the number of crawlers in each segment. We conducted five replicates for each scale species. 


\section{RESULTS AND DISCUSSION}

\section{Scale Phenology}

\section{Pulvinariella mesembryanthemi}

Pulvinariella mesembryanthemi and Pulvinaria delottoi, like other scales in the Coccidae, pass through three immature instars before molting to the adult stage. The three molts occur on the host plant after settling of the first instars or crawlers. Newly molted individuals usually carried the shed cuticular lining of the gut as a small curl of tissue extending from the anus. Detailed descriptions of the instars are given by Gill (1979) for P. delottoi and by Brain (1920), Hodgson (1967), and DeLotto (1967) for P. mesembryanthemi. The life cycles, instar size ranges, and fecundities for both scales are summarized in figure 1.

In 5 years of monitoring in central California we found patterns in the growth and development of populations of $P$. delotto $i$ and $P$. mesembryanthemi consistent with those reported by Donaldson et al. (1978) for the same species in California. Populations of $P$. mesembryanthemi cycled through two generations per year while $P$. delottoi exhibited only a single generation per year. The growth and reproduction schedules of representative populations of both species are shown in figure 2. Bivoltine life cycles were observed for populations of $P$. mesembryanthemi in Sacramento, Yolo, Napa, Alameda, Contra Costa, San Francisco, and Monterey counties. Typically, populations in these areas had two reproductive episodes 6 to 12 weeks in duration in the spring and fall months. Crawler emergence was similarly prolonged, reflecting temporal variation in ovisac formation within populations (fig. $2[A]$ ). In some instances, timing of ovisac production was attributable to exposure. Scales growing on plants in shaded areas and scales growing lower in dense iceplant canopies tended to form ovisacs later than those in direct sun on terminal shoots.

The phenology of $P$. mesembryanthemi populations included reproductive peaks primarily during spring and fall, and at each site populations were consistently bivoltine. However, within the San Francisco Bay area we were able to locate some ovisacs year-round if enough populations were sampled. Variation in the onset of reproduction of $P$ mesembryanthem $i$ populations among sites was sometimes attributable to climatic differences. For instance, one population of $P$. mesembryanthemi from Fort Funston, San Francisco County, was situated on coastal cliffs where the climate was predominately cool and moist. In the fall of 1981 this population began ovisac production 6 weeks later than concurrently monitored populations from Oakland, San Mateo, and Berkeley, even though all four populations were synchronized in early summer. After crawlers emerged and settled in the fall, the Fort Funston population developed at a slower rate than the others. A similar delay in reproduction for coastal populations of the Japanese wax scale, Ceroplastes ceriferus, has been reported for Cape Henry, Virginia (Schultz 1980). Schultz reported that egg hatching in coastal populations was delayed by strong eastern winds that resulted in lower maximum temperatures and asynchronous scale populations.

Male scales of $P$. mesembryanthemi differentiate morphologically from the second instar (fig. 1) and were present at field sites in the interval between periods of ovisac formation (fig. $2[A]$ ). The sex ratio of field populations was always strongly female biased (generally greater than 300:1), and males were totally absent from some field populations. The onset of male differentiation is indicated by the development of a pink or light red coloration over the body surface in the late second instar. Within a few days the color turns to dark 


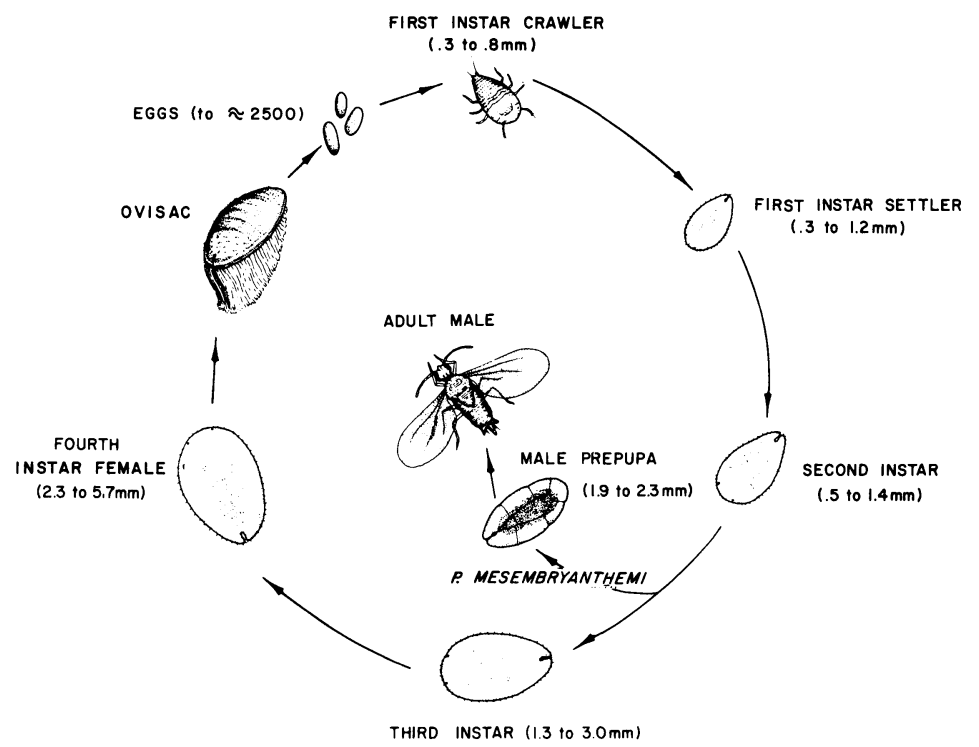

Fig. 1. Life cycle for Pulvinariella mesembryanthemi and Pulvinaria delottoi. Size ranges of instars and maximum observed fecundities for both species are shown. Average instar sizes and fecundity for $P$. delotto $i$ are somewhat greater than $P$. mesembryanthemi.

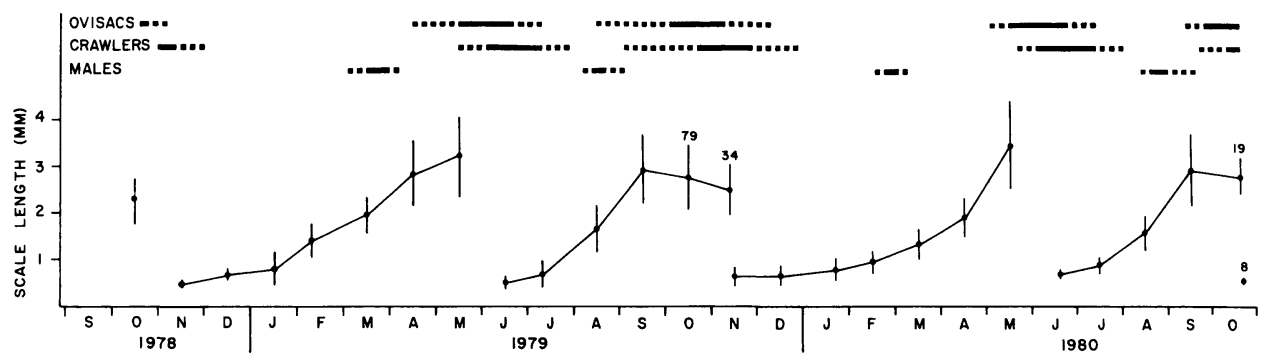

(A) Pulvinariella mesembryanthemi

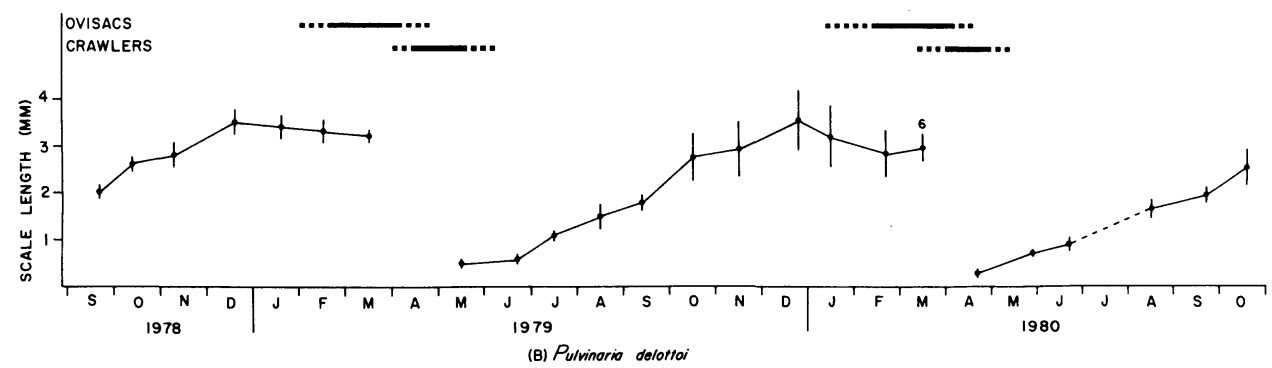

Fig. 2. Growth and development of field populations of $P$. mesembryanthemi from Berkeley (A) and $P$. delottoi from Monterey (B) from 1978-1980. Horizontal bars at the top of each graph indicate the presence of ovisacs, crawlers, and males at field sites. Solid bars indicate when the scale stages were common, and dashed bars indicate when stages were present but uncommon. All points in the growth curves are mean lengths of 100 immature scales unless otherwise indicated. Vertical lines are one standard deviation. 
red brown, and the dorsum of the exocuticle becomes reticulated by a network of lines radiating outward from a central oval. The exocuticle becomes a translucent veil surrounding the prepupa, and eventually the prepupal skin is shed and the winged male emerges (Pesson 1941). Males, which are short-lived and do not feed, die within 3 to 7 days of emergence.

\section{Pulvinaria delottoi}

Field populations of Pulvinaria delottoi also exhibited prolonged reproductive bouts, but ovisac formation and crawler emergence occurred primarily during winter months (JanuaryMarch, fig. $2[B]$ ) at field sites in Monterey, Contra Costa, Alameda, and San Mateo counties. As mentioned previously, this species is univoltine in central California, and at present the known southern extent of its range is Monterey County. In laboratory cultures, $P$. delotto $i$ developed in less than 6 months, suggesting that it may be bivoltine if it establishes in southern California.

Populations of $P$. delottoi typically occupied lower leaves and stems on Carpobrotus shoots than did populations of $P$. mesembryantbemi. This reflects both a difference in settling site selection and slower growth rate of $P$. delottoi compared with $P$. mesembryanthemi. Because tenure in each instar is approximately doubled for immature $P$. delottoi, the host plant has more time to grow, which results in a scale population on the more basal portions of the plant (see also later section).

We never recovered males of $P$. delottoi from field populations, and only a single individual was produced from numerous laboratory cultures in more than 3 years of study.

\section{Geographic Sampling}

During our sampling throughout the known geographic range of $P$. mesembryanthem $i$ in 1982 and 1983 we found extensive latitudinal variation in the developmental state of populations. From samples collected in August 1982, the more southerly populations were progressively more advanced than were the northern populations, as indicated by increasing sizes of immature scales (fig. 3[A]). This trend was evident for populations north of Pismo Beach, San Luis Obispo County (site 5). We attribute these differences to warmer temperature regimes in more southern areas. Hotter summer temperatures of the Central Valley accelerated the growth of the Sacramento population (site 1) relative to populations growing in the cooler climate regimes of Oakland (site 2) and Newark (site 3). However, because winter temperatures are lower in the Central Valley, scales from both areas tended to reproduce on similar schedules in the spring.

Four populations were sampled in Los Angeles County (sites 6-9), and each consisted of ovisacs, crawlers, and all immature instars during this sampling effort as well as those made in December 1982 and April 1983. Variation in the developmental state of populations among sites sampled simultaneously in the Los Angeles area was extreme. For instance, in August one population in Long Beach (site 9) was predominated by first instar settlers with fewer numbers of later instars and ovisacs. Another population from Anaheim (site 8) was within 10 miles, but was composed of primarily second and third instars, though some ovisacs and crawlers were present. 


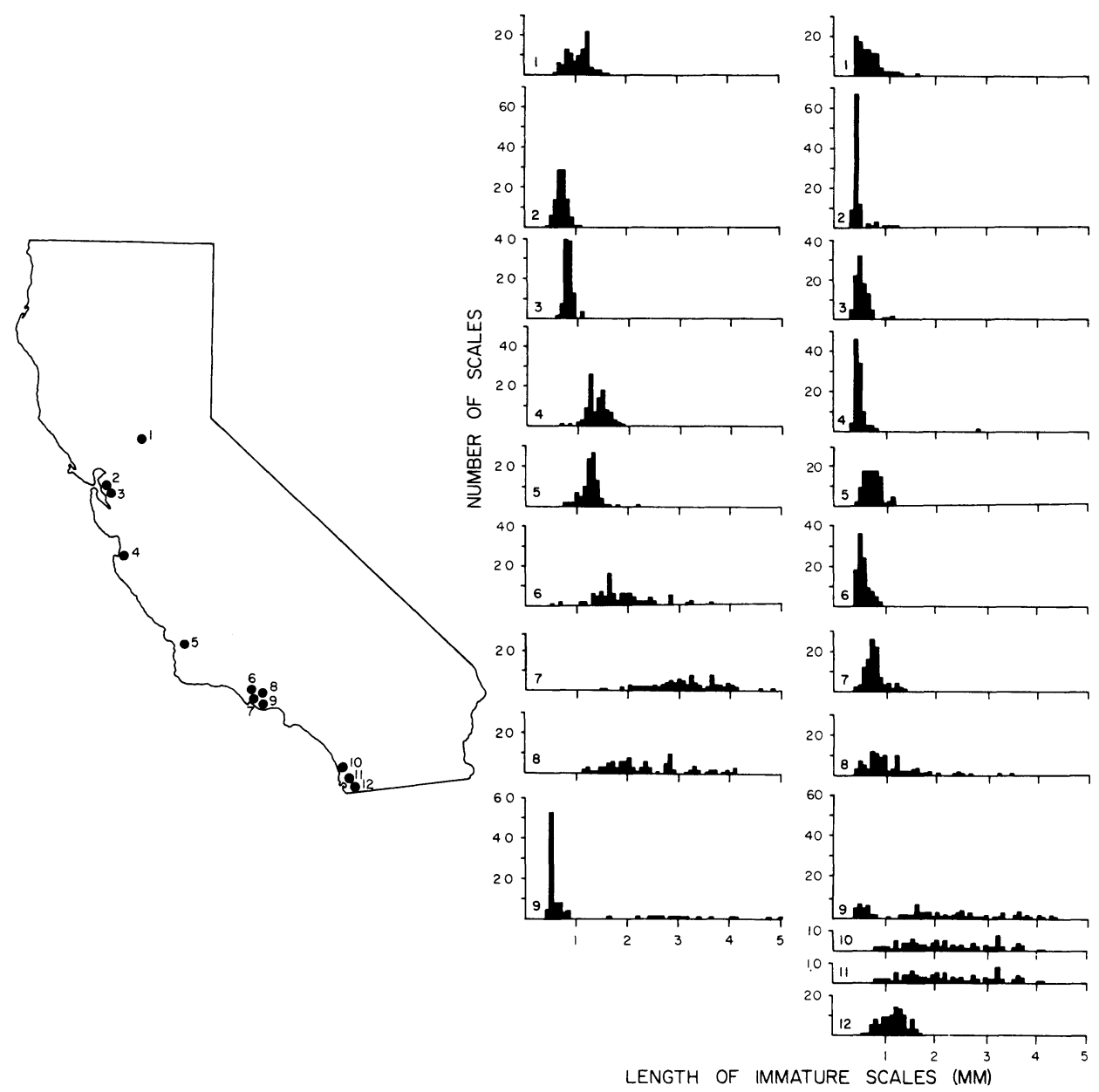

Fig. 3. The lengths of immature $P$. mesembryantbemi collected at California field sites in August $(A)$ and December (B) 1982. One hundred scales were measured from each site. Field site locations are: (1) Sacramento, Yolo County; (2) Oakland, Alameda County; (3) Newark, Contra Costa County; (4) Monterey, Monterey County; (5) Pismo Beach, San Luis Obispo County; (6) Bellflower, Los Angeles County; (7) Long Beach, Los Angeles County; (8) Anaheim, Orange County; (9) Los Angeles, Los Angeles County; (10) Del Mar, San Diego County; and (11 and 12) San Diego, San Diego County.

Three additional scale populations (sites 10, 11, and 12 in figure 3) from San Diego County were included in the December sampling, and these exhibited variation in scale size similar to samples of populations from Los Angeles collected in August. Variance in the distribution of scale lengths increased naturally with mean size and was accentuated by such factors as parasitism that slowed growth and development. Some scales collected in field samples later turned out to be parasitized, though we eliminated any obviously parasitized scales at the time of collection. Additionally, if host-plant patches are colonized more than once and at different times, asynchronous populations can result.

From our samplings in 1982 and 1983 we determined that $P$. mesembryanthemi undergoes three generations in the Los Angeles area. The size distributions of scales collected 
from three sites (Sacramento, Newark, and Los Angeles - sites 1, 3, and 9, respectively, in figure 3) for three sample periods collected at 4-month intervals are shown in figure 4 . The two scale populations from the north (Sacramento and Newark) exhibited similar synchronous developmental patterns. In the August sample, both populations consisted of settled first and second instars. By December both populations had completed a reproductive bout in the fall, and the subsequent generation consisted of first and second instars.

For Sacramento and Newark populations, mean scale sizes in December were smaller than means for August samples demonstrating that both populations had completed less than one full generation in the intervening 4 months (fig. 4). A third population sampled simultaneously in Los Angeles (site 9, fig. 3) was also predominated by first instar settlers in August. The smaller mean length of these scales, compared with the two northern populations in August, indicates they were developmentally behind. In December, this Los Angeles population was reproducing, and the first instar progeny were already settled. As in the Sacramento and Newark populations, scales from Los Angeles progressed less than a full generation in the 4-month interval between the August and December samples.

In the April samples, scales from Sacramento and Newark had developed to the second and third instars; few were in the fourth instar, and none had produced ovisacs. The major peak of reproduction of these two populations occurred in June. In contrast, the scales collected in Los Angeles experienced a warmer winter and were reproductive in April. Ovisacs were abundant, and the earliest crawlers had emerged and settled. Thus, this population of $P$. mesembryanthemi experienced three major reproductive periods within a year: one before the August 1982 sample, one in the interim between the August and December samples, and the third that was in progress when the April 1983 sample was collected. These results are consistent with our laboratory colonies which typically completed a generation in 3 to 4 months.

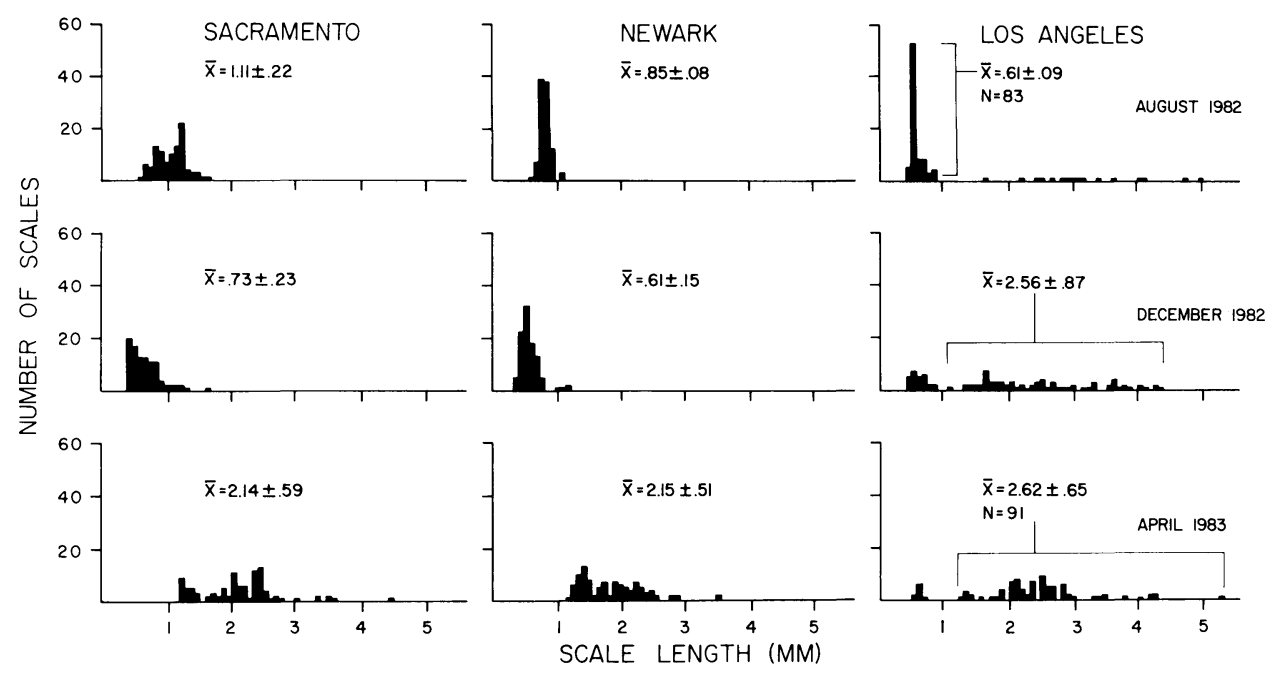

Fig. 4. The lengths of immature $P$. mesembryantbemi collected on three dates from Sacramento, Newark and Los Angeles. One hundred immature scales were measured from each site and used to calculate means. Two generations were represented in all samples collected from Los Angeles, and only individuals in the more common generation were used to calculate means. 


\section{Scale Reproduction}

Pesson (1941) first described males of Pulvinariella mesembryanthemi and reported that they were produced parthenogenetically. Pesson noted that males were distributed in small groups on host plants and suggested that they arose from the same female. Males showed no interest in females, and none of the females examined contained sperm in the spermathecae. Similar findings were reported by Nur (1980, personal communication) who examined females and embryos from material collected in Israel and California. None of the females was inseminated, and few males were discovered in cytological examinations of more than 2,000 embryos. No male embryos were found in adult females from California, while 4 percent of the embryos examined from Israel were males. One female from Israel contained only male embryos (Nur, personal communication). These results are consistent with the suggestion that clusters of males encountered in the field were the progeny of individual females. Males were usually rare or absent from field populations in this study; however, one laboratory colony produced an abnormally high proportion of males ( 28 percent).

We staged several encounters between newly emerged males and females of varying ages of $P$. mesembryanthemi and observed neither mating nor any behavior that suggested a prelude to mating. While males do contain living, motile sperm (Tassan, personal communication), they may represent a relict feature of this species (Nur 1972; Gill, personal communication). Males of $P$. delottoi are undescribed and virtually unknown (Gill 1979); they were not encountered at field sites.

Nur $(1963,1980)$ concluded that $P$. mesembryanthemi reproduces by deuterotoky, a form of parthenogenesis unique to the Coccidae. In this special type of parthenogenesis both males and females are diploid and can be produced from unfertilized eggs. In some species males are functional (e.g., Lecanium putmani and Pulvinaria innumerabilis) and females are produced from fertilized eggs; in others, including iceplant scales, males are rare or absent and their utility is lost (Nur 1972). Because both Pulvinaria floccifera and $P$. innumerabilis produce only males from unfertilized females, parthenogenesis in $P$. mesembryanthemi is apparently derived from diploid arrhenotoky (Nur 1980, personal communication).

\section{Temperature-dependent growth and development}

Laboratory studies on the developmental patterns of $P$. mesembryanthemi populations reared at different temperatures supported field observations on temperature-dependent growth. Scales reared at $24.5^{\circ} \mathrm{C}$ grew faster and reproduced earlier than scales reared at any other temperature (fig. 5 and table 2). That scales matured faster at $24.5^{\circ} \mathrm{C}$ compared with $27^{\circ} \mathrm{C}$ suggests that this species is relatively cool adapted, compared with many other temperate insect species that exhibit maximum growth rates at temperatures over $30^{\circ} \mathrm{C}$. Growth curves for scales reared at $27^{\circ} \mathrm{C}$ and $20.5^{\circ} \mathrm{C}$ were similar and ovisac formation began at 11 and 13 weeks, respectively, for the two populations (table 2 ). Thus, our range of experimental temperatures exceeded that portion of the temperature spectrum where changes in scale-growth rate are linear. Scales reared at all temperatures showed increased growth rates (as shown by steeper slopes in figure 5) after they reached 1.5 to $2.0 \mathrm{~mm}$ in length (second instar). Pulvinaria delottoi exhibited similar temperature-related growth; scales in the $24.5^{\circ} \mathrm{C}$ growth chamber molted to the second instar before scales in the other growth chambers, and when the experiment was terminated these scales were the largest. 


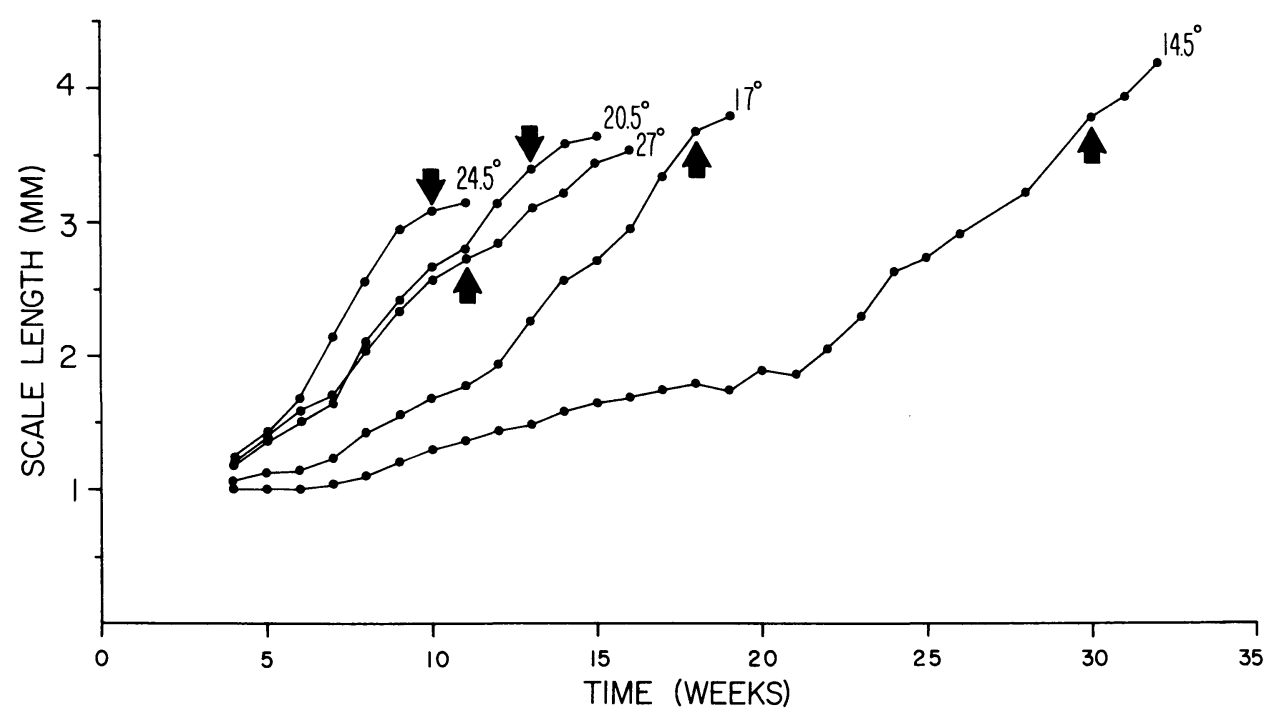

Fig. 5. Growth rates of $P$. mesembryantbemi reared at different temperatures. Sample points for each temperature are mean lengths of 45 immature scales. Arrows indicate when ovisacs first appeared in populations.

TABLE 2. REPRODUCTIVE CHARACTERISTICS OF PULVINARIELLA MESEMBRYANTHEMI POPULATIONS REARED AT CONSTANT TEMPERATURES*

\begin{tabular}{cccccc}
\hline \hline $\begin{array}{c}\text { Temperature } \\
\left({ }^{\circ} \mathrm{C}\right)\end{array}$ & $\mathbf{N}$ & $\begin{array}{c}\text { Crawlers/ } \\
\text { ovisac } \\
(\mathbf{X} \pm \mathbf{1} \text { s.d.) }\end{array}$ & $\begin{array}{c}\text { Ovisac length } \\
(\mathbf{m m}) \\
(\mathbf{X} \pm \mathbf{1} \text { s.d.) }\end{array}$ & $\begin{array}{c}\text { Survivorship } \\
(\%)\end{array}$ & $\begin{array}{c}\text { Time } \\
\text { (weeks) }\end{array}$ \\
\hline 14.5 & 23 & $1349 \pm 623 \mathrm{a}$ & $4.55 \pm .59 \mathrm{a}$ & $14.0 \mathrm{a}$ & 30 \\
17.0 & 24 & $1575 \pm 519 \mathrm{a}$ & $4.60 \pm .44 \mathrm{a}$ & $18.3 \mathrm{a}$ & 18 \\
20.5 & 28 & $895 \pm 416 \mathrm{~b}$ & $3.87 \pm .50 \mathrm{~b}$ & $45.3 \mathrm{~b}$ & 13 \\
24.5 & 20 & $531 \pm 297 \mathrm{bc}$ & $3.65 \pm .33 \mathrm{bc}$ & $47.8 \mathrm{~b}$ & 10 \\
27.0 & 27 & $307 \pm 172 \mathrm{c}$ & $3.45 \pm .33 \mathrm{c}$ & $49.8 \mathrm{~b}$ & 11 \\
\hline
\end{tabular}

*Means in columns followed by different letters are significantly different (Duncan Multiple Range Test, $\mathrm{p}<.05$ ). Scale survivorship is calculated from the number of scales surviving on four host plants, each infested with 100 crawlers. Time in weeks indicates the interval between initial infestation with crawlers and the first appearance of ovisacs in each population.

We found no significant difference in $P$. mesembryanthemi survivorship for populations reared at $20.5^{\circ}, 24.5^{\circ}$, and $27^{\circ} \mathrm{C}$. Scale survivorship rates for insects reared at $14.5^{\circ}$ and $17^{\circ} \mathrm{C}$ were comparable but significantly lower than those reared at the three higher temperatures (table 2).

In addition to differences in growth rate and survivorship, the ovisacs produced by scales reared at different temperatures varied in both size and fecundity. We found a significant and dramatic negative correlation between the length of ovisacs and the rearing temperature. Ovisacs from lower temperatures were larger and on average produced many more crawlers than ovisacs reared at higher temperatures (table 2). For example, there was a 500 percent difference between the average number of crawlers produced at $17^{\circ} \mathrm{C}$ versus $27^{\circ} \mathrm{C}$.

The effects of temperature on the growth and development of $P$. mesembryanthemi populations at field sites can be seen through differences in duration and slope of the growth- 
rate curves in figure $2[A]$. Scales maturing during warm summer months grew faster than those that developed over winter and reproduced in spring. Seasonal differences in generation time were evident in all populations of $P$. mesembryanthemi sampled north of Monterey. This pattern was not evident in the immature stages of $P$. delotto $i$ since the slope of its growth curve appears nearly constant (fig. $2[B]$ ). Neither scale species seems to diapause since overwintering individuals continued to grow and molt.

Decline in mean-scale size for both species (figs. $2[A]$ and $2[B]$ ) during periods of ovisac formation is primarily an artifact of sampling. Iceplant scales do not decrease in size prior to reproduction. In sampling, as the more advanced individuals of a population began ovisac formation, they were excluded from samples of immatures. Immature scales from samples collected during reproductive periods were developmentally slower and included some parasitized and unhealthy individuals. These individuals were generally shorter in length, and most failed to reproduce.

\section{Ovisac Development}

Ovisacs of $P$. mesembryanthemi and $P$. delottoi develop from mature fourth instar females, when the scales are 2.3 to $5.7 \mathrm{~mm}$ long. Small ovisacs that produce few crawlers can be prematurely formed from third or fourth instars, if scales are removed from the host plant, or if the plant tissues supporting the scale die. Initiation of ovisac formation begins with the appearance of a red, marginal ring on the cuticle of the insect with a concurrent secretion of a waxy flocculance from the dorsal wax glands. This appearance is maintained for 1 to 5 days before production of the white, fibrous ovisac which is formed by secretions from the ventral wax glands along the margin of the body. The posterior of the female's body elevates from the substrate as the fibrous ovisac is formed, but the mouthparts may remain imbedded in the plant tissue, and it is possible that feeding continues during the early stages of ovisac formation. Eventually, the body of the scale shrivels and darkens, developing several transverse folds near the center.

Completion of the ovisac structure may require 6 to 12 days from its initiation, but egg deposition usually begins on the third or fourth day. Oviposition may continue for as long as 18 days, but is generally completed by the ninth day. Reproductive potentials of both $P$. mesembryanthemi and $P$. delotto $i$ are great, and individuals of either species are capable of producing broods in excess of 2,400 (fig. 1). The average fecundity values, however, are much lower (e.g., 350 to 800 crawlers per ovisac) and vary with temperature (table 2), scale density, host-plant species, and edaphic conditions of the host (Washburn and Frankie, unpublished data). The average fecundity and ovisac size of $P$. delotto $i$ is somewhat larger than for $P$. mesembryanthemi. Egg mortality within the ovisac is low and rarely exceeds 10 per cent (but see discussion), and the high reproductive potential of these scales has certainly been important in their establishment and spread.

Crawlers begin eclosion from eggs before oviposition is completed, and eggs and crawlers were commonly found together in ovisac dissections. Each ovisac has a vertical cleavage line that extends from approximately the anus to the substrate at the base of the ovisac. As crawlers begin moving actively inside the ovisac, the cleavage line splits and the insects escape. Individual ovisacs may produce emerging crawlers as long as 20 days, but most crawlers leave the ovisac within 5 to 10 days after emergence begins (fig. 6). This extended emergence of crawlers is also reported for the Mediterranean black scale, Saissetia oleae, (Podder, Bar-Zacay, and Rosen 1979), and it reflects both the prolonged oviposition period and the difficulty crawlers encounter while escaping the sticky, fibrous wax of the ovisac. 


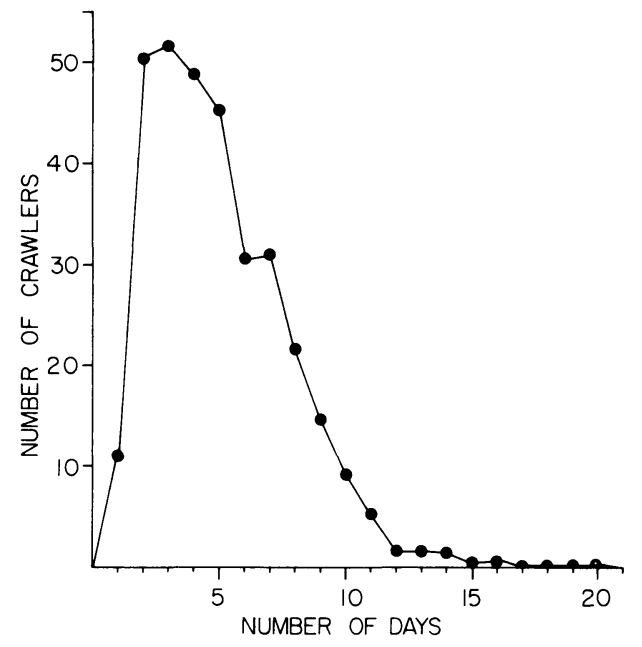

Fig. 6. The emergence pattern of $P$. mesembryanthemi crawlers from ovisacs. Each point represents the total number of crawlers emerged from 20 ovisacs. Day 1 for each ovisac is the first day crawlers emerged.

\section{Crawler Biology}

In scale insects, crawlers are responsible for natural dispersal and selection of feeding sites (Flanders 1970). These behaviors are influenced by at least three types of factors: (1) innate behavior patterns which initiate wandering, (2) availability of acceptable settling sites, and (3) ambient environmental conditions such as illumination, temperature, humidity, and wind velocity (Beardsley and Gonzalez 1975). Our results indicate these factors are also important in the success of iceplant scale crawlers.

After emerging from ovisacs, iceplant scale crawlers disperse over the host plant seeking suitable feeding sites. For many species if suitable feeding sites are not available crawlers engage in long-range dispersal by wind (e.g., Quayle 1916; McClure 1976; Stephens and Aylor 1978). Wind is apparently responsible for the rapid spread of $P$. mesembryanthem $i$ in many areas of California (Washburn and Frankie 1981). We have captured iceplant scale crawlers on Tanglefoot traps at heights $50 \mathrm{~m}$ above the ground, attesting to the effectiveness of wind transport. In contrast to previous reports (e.g., Cornwell 1960; Southwood 1962 ) wind dispersal is apparently not completely a passive or accidental process for dissemination of scale crawlers (see also Willard 1976). It has been found that both $P$. delotto $i$ and $P$. mesembryanthem $i$ crawlers exhibit a specific behavior which increases the probability of aerial transport. When exposed to air streams of 1.8 to $4.0 \mathrm{~m}$ per sec, dispersing crawlers will orient facing downwind and stand on their mesothoracic and metathoracic legs. This posture exposes the maximum body surface area to the wind, which increases the frictional drag and enhances removal from the substrate and into the air column (Washburn and Washburn 1984).

Although the geotactic responses of scale crawlers have seldom been investigated (Beardsley and Gonzalez 1975), some species like the armored California red scale, Aonidiella aurantii, are known to be negatively geotaxic (McLaren 1971). Similarly, in our tests crawlers of $P$. mesembryanthemi and $P$. delotto $i$ exhibited negative geotaxy. In gravity response tests performed in darkened enclosures, we found that most crawlers were trapped on the upper portions of discs bordered by Tanglefoot, and routinely crawlers were observed accumulating at the tips of leaves in both laboratory and field populations. In the five light 
response tests on crawlers of each species, more than 80 percent of the individuals were found in the illuminated segment of the plexiglass bar, indicating a positive phototaxic response. Strong phototaxic behavior is a major feature of scale crawler biology and is the dominant cue for dispersal (Bennassay 1961, Beardsley and Gonzalez 1975). Geotaxic and phototaxic responses can facilitate location of feeding sites by moving crawlers over host surfaces (Brown 1958), and if feeding sites are not available, these taxic responses serve to locate crawlers at the ends of terminal shoots where wind dispersal is more likely (Willard 1976; Washburn and Washburn 1984).

Selection of an appropriate feeding site is critical for the first instar crawlers. Failure to settle successfully is a major mortality factor for populations of many scale species, and generally mortality is highest for first instars (e.g., Oda 1963; Beardsley and Gonzalez 1975; Podder, Bar-Zacay, and Rosen 1979). Observations on laboratory and field populations of $P$. mesembryanthem $i$ and $P$. delotto $i$ indicate that most mortality (excluding parasitism) occurs during the first instar. For example, in figure 7 we show the survivorship curves for four representative laboratory populations of $P$. mesembryanthemi. These curves depict survivorship trends of four sets of populations, each reared under unique edaphic conditions. Curves similar to these were characteristic of laboratory populations of various densities reared under a wide spectrum of environmental conditions. Similarly, we frequently encountered large numbers of dead settlers at field sites, indicating that settling is a critical period for crawlers under more natural conditions.

We found differences in the settling preferences of $P$. mesembryanthemi and $P$. delotto $i$ crawlers among leaves of different sizes. Because crawlers of both species were initially introduced onto the lowest leaf pairs of plants, the oldest leaves of the plant were encountered first as the crawlers began foraging. If these were rejected, the insects could sample progressively younger leaves as they climbed the plant until a suitable settling site was found. Introduction of crawlers onto the basal portions of the plant is comparable to emergence from ovisacs under natural conditions and does not bias feeding site selection.

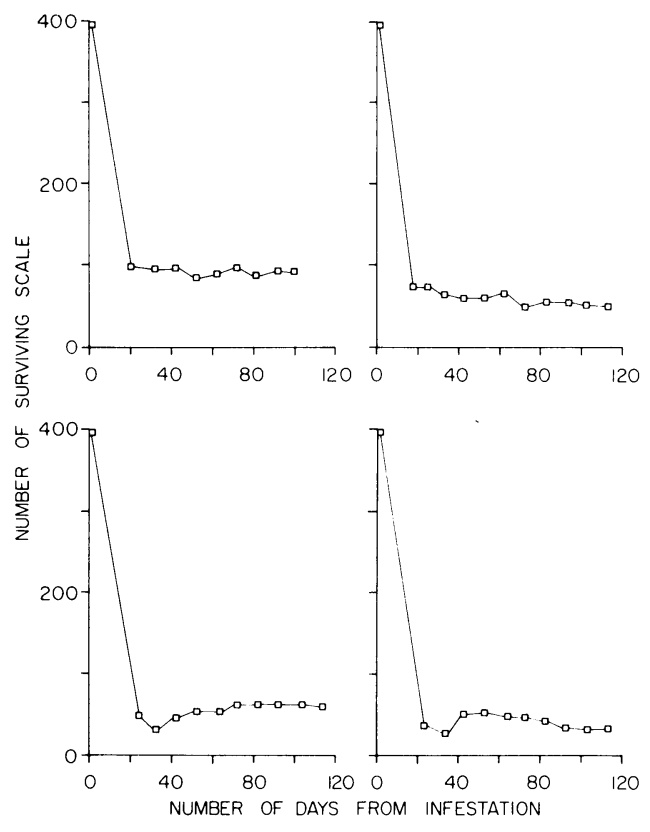

Fig. 7. Survivorship curves for four laboratory populations of $P$. mesembryanthemi. Each curve depicts the number of surviving scales from a set of four host plants, each infested with 100 newly emerged crawlers. Each host-plant set was maintained under different edaphic conditions (e.g., water and fertilizer regimes) both before and after infestation with crawlers. The apparent increase in scale numbers after infestation resulted from surviving settlers that were not detected in early counts. 
Individual crawlers are thus able to sample a spectrum of potential settling sites as they move up the plant, and if none is acceptable they have the option of wind dispersal. In general, crawlers of $P$. delottoi tended to settle on more mature, larger leaves than $\operatorname{did} P$. mesembryanthemi crawlers (fig. 8). Pulvinaria delottoi occupied more than 70 percent of leaves in all size categories larger than 20 to $29 \mathrm{~mm}$. In contrast, the 20- to 29-mm leaf class had the highest proportion of leaves occupied with $P$. mesembryanthemi settlers, and classes with progressively larger leaves had lower colonization frequencies. Settlers of $P$. mesembryanthemi were completely absent from the largest leaf class (70 to $79 \mathrm{~mm}$ ), while nearly 70 percent of the leaves in this class were settled by $P$. delottoi.

In the lower histogram of figure 8 the distributions of successful settlers of both species among leaf classes are shown. The majority of the surviving population of $P$. mesembryanthem $i$ settlers was concentrated on smaller-sized leaves than $P$. delotto $i$ settlers, although there was extensive overlap between the two distributions. These results are consistent with field observations where early instars of $P$. delottoi are found on more mature foliage of Carpobrotus. The high proportion of $P$. mesembryanthemi settlers on the 50- to 59-mm leaf class resulted primarily from a single leaf colonized by 19 scales. While the two species exhibit definite preferences, the wide range of leaf sizes successfully colonized by both species suggests that neither species is limited to a particular class of leaves. Some biochemical, physiological, and physical features of leaves change as they mature (e.g., concentration of phenolic compounds and leaf toughness increase); thus, host plants offer a gradient of leaf resources.

Data on settling distributions suggest that scales respond to one or more leaf characteristics that correlate with leaf age. In both replicates, where crawler settling ability was tested in gelatin capsules on young leaves, mature leaves, and stems, the two species showed significant differences in colonization success among tissues (table 3). Although overall

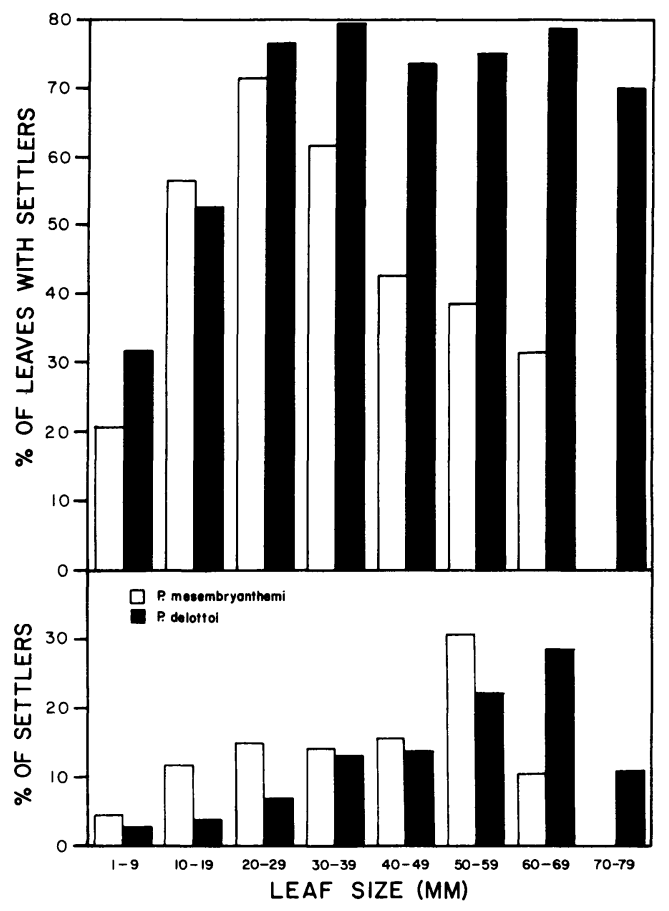

Fig. 8. Settling preferences of $P$. mesembryanthemi and $P$. delottoi crawlers on leaves of various sizes. For each species 100 crawlers were introduced at the base of each of seven host plants. Histograms reflect the distribution among leaves of surviving scales 1 week after introduction $(\mathrm{N}=430$ for $P$. mesembryanthemi, $\mathrm{N}=431$ for $P$. delottoi). The upper histogram depicts the proportion of leaves in each size class colonized by crawlers of the two species. The lower histogram depicts the proportion of surviving scales on each leaf size class. There were between 11 and 54 leaves per class for plants in settling tests for each species. 
TABLE 3. SETTLING SUCCESS OF P. MESEMBRYANTHEMI AND P. DELOTTOI ON YOUNG LEAVES, MATURE LEAVES, AND STEMS OF CARPOBROTUS

\begin{tabular}{lccc}
\hline \hline & \multicolumn{3}{c}{ Percent of successful settlers } \\
\cline { 2 - 4 } Scale species & Young leaves & Mature leaves & Stems \\
\hline Replicate $1^{*}$ & & & \\
$P$. mesembryanthemi & 56 & 19 & 0 \\
$P$. delottoi & 81 & 66 & 4 \\
Replicate 2* & & & \\
$P$. mesembryanthemi & 45 & 6 & 0 \\
$P$. delottoi & 82 & 82 & 15 \\
\hline
\end{tabular}

*Each replicate consisted of an initial population of 100 newly emerged crawlers of each species on each type of plant tissue. See text for explanation.

settling success of $P$. mesembryanthemi was lower than $P$. delottoi for the tested tissues, the two species had similar settling success in the preference tests (fig. 8). In both replicates $P$. delottoi experienced equivalent settling success rates on young and mature leaves (ANOVA, $\mathrm{p}>.05$ ), and much lower success rates on stems (ANOVA, $\mathrm{p}<.001$ ). Pulvinariella mesembryanthemi, in contrast, showed significantly higher success rates on young leaves than mature leaves (ANOVA, $\mathrm{p}<.01$ ), and none of the crawlers successfully settled on stems.

As leaves mature, the epidermal layer toughens and becomes more difficult to penetrate, but physical penetration of mature leaves and stems did not appear to limit settling success. Many unsuccessful crawlers of both species died on mature leaves and stems with their stylets inserted in the substrate, suggesting that tougher epidermis alone is not an effective deterrent against scale settling. Similar results have been reported by Blackmore (1981) for Icerya seychellarum feeding on euphorbs on Aldabra Atoll. Blackmore found that thickened tissues were not an important factor influencing plant susceptibility and that scale stylets readily penetrated thick-walled cells in the sclerenchyma and xylem.

\section{Scale Feeding}

The distribution of vascular bundles in leaves of Carpobrotus spp. is shown in figure 9. Leaves are triangular in cross section and have major bundle elements traversing the longitudinal leaf axis along the three corners in the lower levels of the mesophyll tissue. An extensive network of smaller vascular elements extends through the intercellular spaces of the most proximal mesophyll cells on the three sides of the leaves. The epidermal and underlying mesophyll cells are the primary sites of photosynthesis; together with the vascular elements they are the major sources of amino acids and soluble proteins in iceplant leaves (Washburn and Frankie, unpublished data). The network of vascular bundles has radial vessels extending to the largest vein that lies in the center of the leaf. The entire central core of the leaf is devoted to water storage; under xeric conditions this stored water is recruited, causing the leaves to shrink and curve inward on their sides.

The distance between the leaf surface and the scale-feeding sites in the vascular network is positively correlated with leaf length (fig. 10). It is important to note that the plotted values are averages for individual leaves; some vascular elements lie deep and some lie shallow. However, the standard deviations for all averages were 15 percent or less of the 


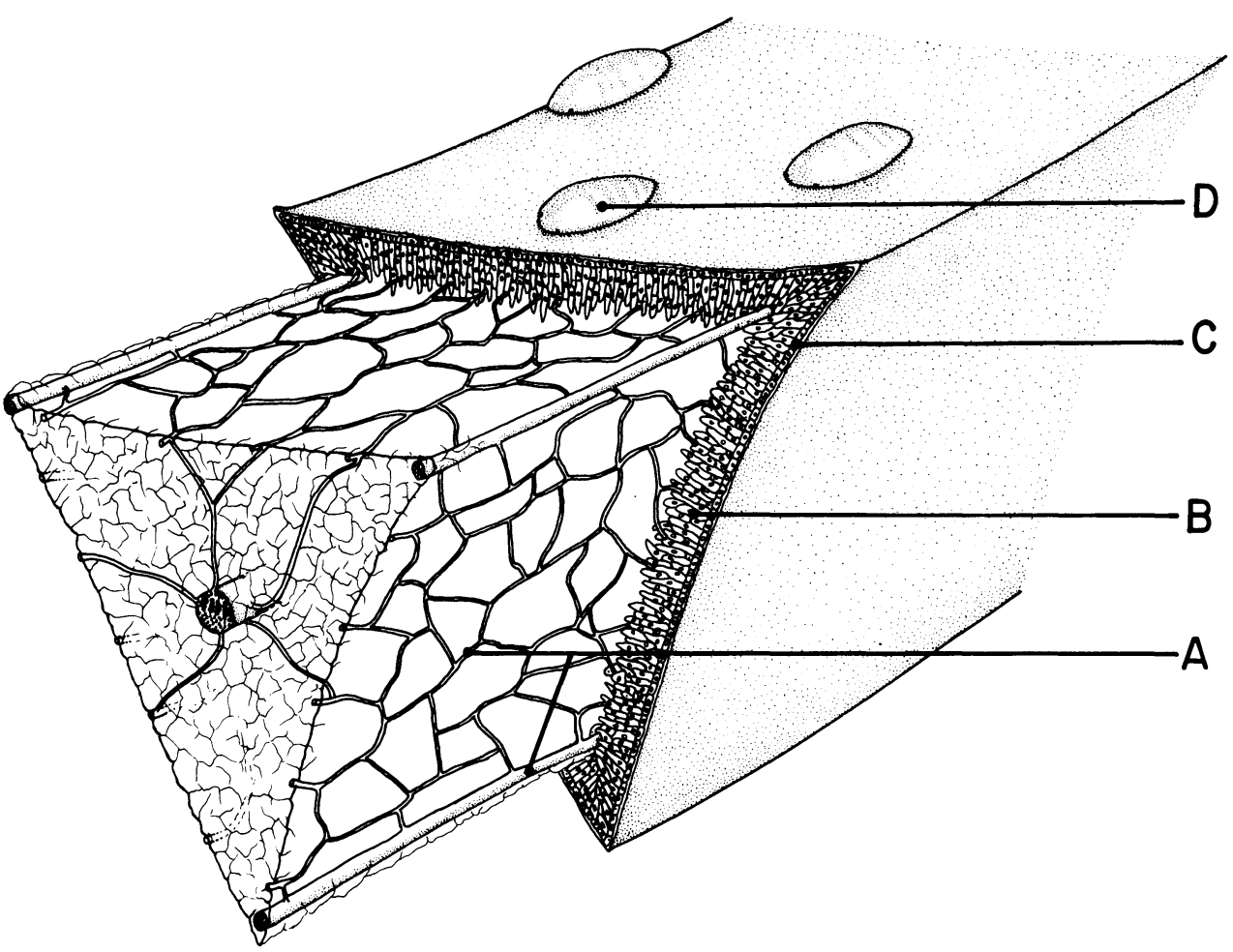

Fig. 9. Cross section of a leaf of Carpobrotus showing the location of vascular elements (A) underlying the mesophyll (B) and epidermis (C). Three scales (D) are shown on the dorsal surface of the leaf.

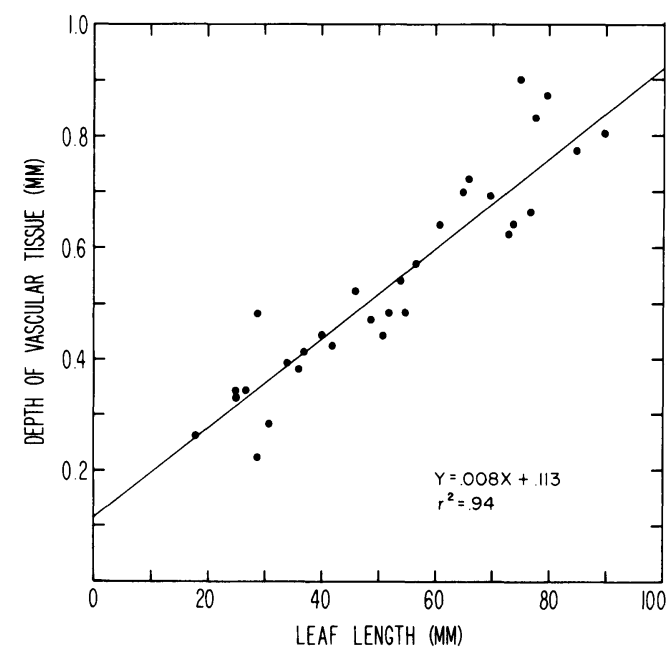

Fig. 10. The relationship between the length of Carpobrotus leaves and the depth of the vascular network. Each point represents the mean of nine distances measured from the leaf surface to the vascular network on a single leaf. 
mean values, indicating that the depth of the vascular network is fairly uniform within leaves. In the early stages of leaf development (leaves less than $20 \mathrm{~mm}$ ) the vascular elements are only partially formed, and the network is not contiguous. This may explain why many of the smallest leaves were only sparsely colonized in the tests of crawler-settling preference (fig. 8).

Carpobrotus leaves of greater lengths have progressively deeper vascular bundles. Depth of bundles is not affected by availability of soil moisture, since under xeric conditions leaf shrinkage occurs in the central areas of the leaf below the mesophyll layer.

Suitability of a given leaf as a settling and feeding site for scales will, in part, be determined by accessibility and nutritional status of the vascular elements. We evaluated one aspect of accessibility by measuring the stylet lengths of scales of varying sizes and comparing them with the depth of vascular bundles. For both $P$. mesembryanthemi and $P$. delotto $i$ we found a significant linear relationship between stylet length and scale length (fig. 11). As scales increase in size, there is a concommitant increase in the length of the feeding stylets. Since scales tend to remain stationary after settling, the longer stylets of later instars allow insects settling on young leaves to maintain contact with the vascular network which becomes more deeply imbedded as the leaf matures.

We found no significant difference between the stylet lengths of first instar settlers of the two species, $.41 \pm .08(\mathrm{~N}=16)$ for $P$. mesembryanthemi and $.45 \pm .09(\mathrm{~N}=18)$ for $P$. delotto $i, \mathrm{t}=1.33, \mathrm{p}>.05)$. These data indicate that crawlers of $P$. delotto $i$ were not more successful than $P$. mesembryanthem $i$ in the settling tests in reaching the deeper vascular bundles on mature leaves.

The average stylet lengths for settlers of $P$. mesembryanthem $i$ and $P$. delotto $i$ are approximately equal to the average depth of the vascular network on leaves in the 30 - to $40-\mathrm{mm}$ size class (fig. 11). On smaller leaves settling first instars should have access to the vascular network within the leaf; on larger leaves the stylets are too short to secure feeding sites in the majority of vascular bundles. Since crawlers do successfully colonize leaves larger than $40 \mathrm{~mm}$, they must either be able to locate shallower vascular bundles or utilize alternate feeding sites. It is possible that settlers can tap nutrients from individual mesophyll cells before invading a vascular bundle. This would be consistent with our observation that first
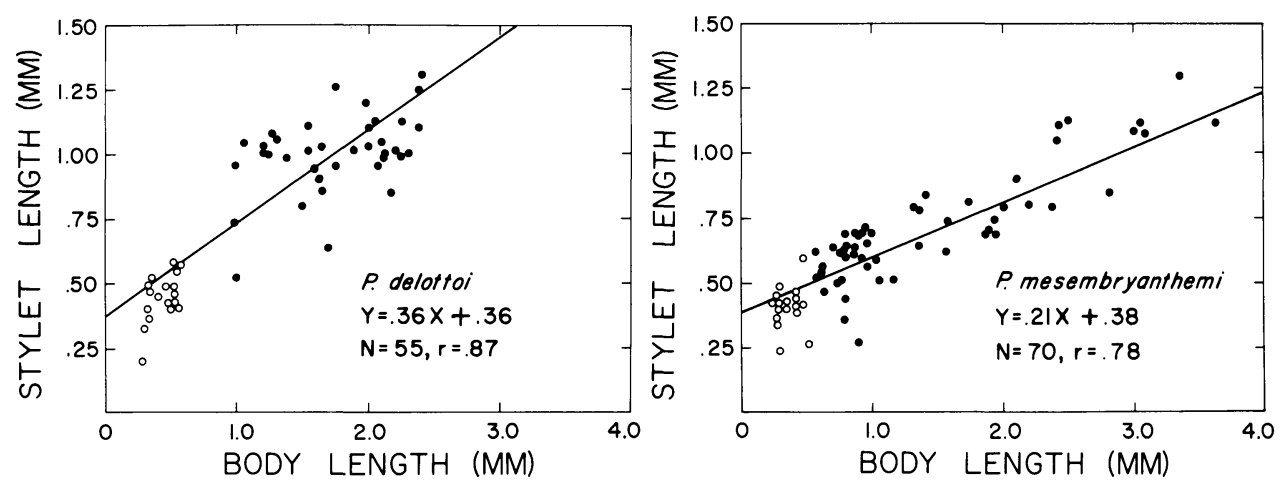

Fig. 11. The relationship between body length and stylet length for $P$. mesembryanthemi and $P$. delottoi. Stylet lengths are measured from the tip to the junction with the body. Open circles represent first instar settlers; closed circles represent later instars. Line equations were determined by leastsquares regression. 
instar settlers do not produce honeydew, a consequence of feeding on vascular elements with high turgor pressure (Auclair 1963, and references therein). Armored scales have been reported to tap individual cells for nutrients (e.g., Heriot 1934), but more careful investigations are necessary to establish the importance of intracellular feeding in scale nutrition.

\section{Host-Plant Range}

Pulvinariella mesembryanthemi has been reported from a variety of succulent species in the Aizoaceae. In the Old World the scale fed on Mesembryantbemum spp. in Egypt (Hall 1922), Spain (Douglas 1887), and Zimbabwe, formerly Rhodesia (Hodgson 1967). The primary food plant in South Africa is Carpobrotus edulis (DeLotto 1967), but because the taxonomy of these two genera of Aizoaceae is not stabilized, it is difficult to provide accurate species names from these regions (W. Ferren, personal communication). In California this iceplant scale has been reported from ornamental plantings of Lampranthus and Carpobrotus spp. in the Aizoaceae (Donaldson et al. 1978; Moore et al. 1979).

Laboratory results of host-range tests of species in the Aizoaceae are shown in table 4. Susceptibility to herbivore attack often varies among individuals of a species, and for many

TABLE 4. EVALUATION OF SELECTED SPECIES OF AIZOACEAE AS HOSTS FOR P. MESEMBRYANTHEMI*

\begin{tabular}{|c|c|c|c|c|c|c|c|c|}
\hline \multirow[b]{2}{*}{ Plant species } & \multicolumn{8}{|c|}{ Sampling periods } \\
\hline & No. plants & 1 & 2 & 3 & 4 & 5 & 6 & Class \\
\hline Astrida berrei & 6 & + & + & + & + & $\mathrm{O}$ & & 1 \\
\hline Berganthus glenensis & 2 & M & - & & & & & 3 \\
\hline Berganthus scarpiger & 6 & + & + & + & + & $\mathrm{O}$ & & 1 \\
\hline Carpobrotus aequalateris & 10 & + & + & + & $\mathrm{O}$ & & & 1 \\
\hline Carpobrotus edule & 10 & + & + & + & $\mathrm{O}$ & & & 1 \\
\hline Carpobrotus murii & 10 & + & + & + & $\mathrm{O}$ & & & 1 \\
\hline Cepbalophyllum alstonii & 3 & M & - & & & & & 3 \\
\hline Cepbalophyllum subulatoides & 5 & + & + & + & + & $\mathrm{O}$ & & 1 \\
\hline Cephalophyllum baylisii & 10 & + & + & + & + & $\mathrm{O}$ & & 1 \\
\hline Cheiridopsis aspera & 2 & + & + & + & + & $\mathrm{O}$ & & 1 \\
\hline Cheiridopsis candidissima & 1 & + & + & + & + & $\mathrm{O}$ & & 1 \\
\hline Cheiridopsis inaequalis & 3 & + & + & + & $\mathrm{O}$ & & & 1 \\
\hline Cheiridopsis purpurea & 4 & + & + & + & $\mathrm{O}$ & & & 1 \\
\hline Cheiridopsis purpurescens & 4 & + & + & + & $\mathrm{O}$ & & & 1 \\
\hline Conicosia pugioniformis & 4 & + & $\mathrm{M}$ & - & & & & 3 \\
\hline Conophytum maximum & 1 & - & & & & & & 3 \\
\hline Conophytum muscosipapillatum & 1 & - & & & & & & 3 \\
\hline Conophytum saxetanum & 1 & + & + & + & + & $\mathrm{O}$ & & 1 \\
\hline Cylindrophyllum tugwelliae & 4 & + & + & + & + & $\mathrm{O}$ & & 1 \\
\hline Delosperma tradescantoides & 5 & + & + & + & $\mathrm{O}$ & & & 1 \\
\hline Delosperma sp. & 1 & + & + & + & $\mathrm{O}$ & & & 1 \\
\hline Disphyma australe & 4 & + & + & + & $\mathrm{O}$ & & & 1 \\
\hline Dorotbeanthus bellidiformis & 3 & - & & & & & & 3 \\
\hline Drosantbemum speciosum & 5 & - & & & & & & 3 \\
\hline Faucaria duncanii & 4 & + & + & + & $\mathrm{O}$ & & & 1 \\
\hline Faucaria paucidens & 1 & + & + & + & + & $\mathrm{O}$ & & 1 \\
\hline Faucaria tuberculosa & 1 & + & + & + & + & $\mathrm{O}$ & & 1 \\
\hline Faucaria sp. & 4 & + & + & + & + & + & $\mathrm{O}$ & 1 \\
\hline Fenestraria aurantiaca & 2 & + & + & + & + & $\mathrm{O}$ & & 1 \\
\hline
\end{tabular}


of our plant species only a few individuals were available for testing. Because of this, our data on acceptable hosts are more reliable than data from species that failed to support scales. Of the 48 plant species tested, $P$. mesembryanthemi completed development on 34 species and hybrids in 21 genera. However, we found pronounced differences in the performances of scale populations reared on different species, and we divided the plants into three categories based on these scale responses (see table 4). First, some plant species (e.g., Berganthus glenensis, Cephalophyllum alstonii, and Lampranthus aurantiacus) were inadequate hosts (class 3 in table 4 ) on which scales failed to complete development. Either scales failed to successfully settle or, if they did settle, individuals remained small and died by the third instar. In some cases (e.g., Hereroa rebneltiana) scales persisted for several months before succumbing, but in all cases $P$. mesembryanthem $i$ failed to reproduce.

In another class of hosts, scales successfully reproduced, but survivorship was very low $(<1$ percent) with only a few individuals maturing to the ovisac stage. These species (class 2 in table 4) are designated marginal hosts (e.g., Machairophyllum acuminatum and Stomatium dulthiae). Ovisacs that developed on these plants were small and produced few crawlers.

We determined 29 plant species and hybrids that appeared to be suitable hosts. On these plants (class 1 in table 4) scale developmental rate was variable, but survivorship was

TABLE 4. CONTINUED

\begin{tabular}{|c|c|c|c|c|c|c|c|c|}
\hline \multirow[b]{2}{*}{ Plant species } & \multicolumn{8}{|c|}{ Sampling periods } \\
\hline & No. plants & 1 & 2 & 3 & 4 & 5 & 6 & Class \\
\hline Gibbaeum angulipes & 4 & + & + & + & + & $\mathrm{O}$ & & 1 \\
\hline Glottipbylum nelii & 7 & M & - & & & & & 3 \\
\hline Glottiphylum oligocarpum & 1 & M & - & & & & & 3 \\
\hline Graptopetalum amestbystinum & 5 & - & & & & & & 3 \\
\hline Hereroa rebneltiana & 3 & + & $M$ & - & & & & 3 \\
\hline Khadia beswickii & 3 & + & + & + & + & + & $\mathrm{O}$ & 1 \\
\hline Lamprantbus aurantiacus & 5 & - & & & & & & 3 \\
\hline Lamprantbus glaucus & 3 & - & & & & & & 3 \\
\hline Machairopbyllum acuminatum & 2 & M & M & $M$ & $M$ & $\mathrm{O}$ & & 2 \\
\hline Macbairophyllum bijlii & 5 & $M$ & M & M & M & - & & 2 \\
\hline Mitropbyllum berrei & 3 & + & + & + & + & $\mathrm{O}$ & & 1 \\
\hline Orthopterum coegana & 2 & + & + & + & + & + & $\mathrm{O}$ & 1 \\
\hline Ruschiantbus falcatus* & 2 & + & + & + & & & & \\
\hline Rusbia granitica & 4 & + & + & $M$ & - & & & 2 \\
\hline Rusbia berrei & 1 & + & + & + & + & + & $\mathrm{O}$ & 1 \\
\hline Rusbia stenopbylla* & 3 & + & + & & & & & \\
\hline Scopelogena verruculata & 3 & + & + & + & + & $\mathrm{O}$ & & 1 \\
\hline Stomatium dultbiae & 3 & + & + & M & M & - & & 2 \\
\hline Titanopsis scbwantesii & 3 & + & + & + & $\mathrm{O}$ & & & 1 \\
\hline Trichodiadema invalaris & 4 & + & + & M & $M$ & - & & 2 \\
\hline
\end{tabular}

*The number of individual plants tested for each species is shown in the first column. Sample periods were at 3-week intervals from the date of infestation with crawlers. Healthy scale populations are indicated by $(+)$. The absence of living scales is indicated by $(-)$; the symbol $(\mathrm{M})$ indicates the presence of few surviving scales (see text for explanation). The first sample period during which ovisacs appeared on each host species is shown by the symbol $(\mathrm{O})$. Numbers in the last column indicate the relative suitability of each species as a host: $1=$ variable developmental rate and high survivorship, 2 = slow developmental rate and low survivorship, and 3 = inadequate host. Asterisks after plant species names indicate cases where hosts died before complete development of the scale population. 
consistently high. Populations on these plants produced large, robust ovisacs with many crawlers within 12 to 18 weeks after infestation. The time of ovisac initiation was variable among different species even within a genus. For example, scales reared on Faucaria duncanii began reproducing after only 12 weeks while those on Faucaria sp. began reproducing after 18 weeks. For plant species where more than one host individual was tested, populations on different individuals reproduced on similar schedules despite the fact that both plant size and scale density varied, and both of these factors can influence scale developmental rate. Apparently, differences in developmental rate among adequate hosts is, in part, due to characteristics of the individual species of Aizoaceae. These results are similar to those reported by Stoetzel and Davidson (1973) who found scale phenology of the obscure scale, Melanaspis obscura, varied between two sympatric congeneric oaks.

Pulvinaria delottoi is known from Cheiridopsis inaequalis (Aizoaceae) and Crassula lycopodioides (Crassulaceae) from South Africa and Sedum, Lamprantbus, and Carpobrotus spp. from ornamental landscapes in California (Gill 1979). Additionally, it has colonized at least one native species of Dudleya (Crassulaceae) in Monterey County (Shoener, personal communication). In laboratory cultures, $P$. delotto $i$ completed development on Carpobrotus aequalateris, C. murii, C. edulis, Cheiridopsis inaequalis, Titanopsis schwantesii, and Lamprantbus glaucus. The actual host range of this species is probably much greater, but we did not examine its development on all of the species listed in table 4 .

\section{CONCLUSIONS}

Pulvinariella mesembryantbemi and Pulvinaria delottoi are well-established, exotic pests of aizoaceous and crassulaceous ornamentals in California. Since $1971 P$. mesembryanthemi has spread to 24 counties (table 1); $P$. delottoi currently has a more restricted range and occurs in only seven counties in the vicinity of the San Francisco Bay. We expect this species to eventually develop a range similar to $P$. mesembryanthemi. The rapid spread of the scales has been facilitated by a high reproductive potential and active wind dispersal. Because scale crawlers can survive up to 9 days without feeding, wind transport can effectively disperse living airborne crawlers over great distances. Because iceplants are commonly propagated from cuttings and immature scales are small, green, and inconspicuous, additional dispersal has undoubtedly occurred by accidental transport of infested plant material. The $1981 \mathrm{Kern}$ County population of $P$. mesembryanthemi (table 1 ), which was discovered at a nursery and eradicated, was apparently established in this manner (Tassan and Cassidy, personal communication).

The time to ovisac formation and brood size of $P$. mesembryanthemi varies with temperature. At constant temperatures in the range of $17.5^{\circ}$ to $27^{\circ} \mathrm{C}$, there is a dramatic negative correlation between brood size and temperature. However, at cooler temperatures developmental time is longer and survivorship is lower, which offsets the higher reproductive output.

Because Carpobrotus and other genera of ornamentals in the Aizoaceae are damaged by frost, these hosts are limited to areas of the state with mild temperature regimes. Both scale species appear to be able to live in all climatic regimes where iceplants are cultivated, as documented in our temperature studies and the rapid spread of the pests (primarily $P$. mesembryanthemi) onto ornamentals throughout the state. Iceplants are planted in the hot, dry interior of the Central Valley, and here the high summer temperatures can adversely affect eggs and first instars of P. mesembryantbemi. At field sites in Sacramento and Yolo counties and in greenhouse populations we have observed a high mortality ( $>90$ percent) of 
eggs and crawlers inside some ovisacs experiencing temperatures in excess of $38^{\circ} \mathrm{C}$. Newly settled crawlers also suffer high mortality at these temperatures. Temperature-induced mortality has been reported for early instars of other scales experiencing comparable temperature regimes (Collinge 1911; Quayle 1911; Neunschwander and Paraskakis 1980; Milne 1981), indicating the importance of this abiotic factor for scale success. At present, we lack field observations on $P$. delotto $i$ since it has not invaded landscapes in the Central Valley, but we have observed temperature-related mortality similar to $P$. mesembryanthem $i$ in greenhouse cultures.

Longevity of crawlers of both species is also strongly influenced by relative humidity. We have observed that in 100 percent humidity crawlers may live as long as 9 days while in 50 percent humidity most crawlers died after only 3 days. In drier areas of the state, like the Central Valley, extremes of temperature and humidity may dictate scale phenology by reducing reproductive success and selectively eliminating the youngest age classes of the scale. This mechanism may reduce summer reproductive success and help maintain spring and fall reproduction schedules of $P$. mesembryanthemi. Our results with these insects reiterate the importance of wind, temperature, and humidity in determining crawler success (Beardsley and Gonzalez 1975).

The slower rate of spread of $P$. delotto $i$ throughout the state is primarily due to its longer generation time, fewer dispersal periods, and higher mortality rates. Because $P$. delotto $i$ is univoltine in northern California, it only produces the dispersing crawlers once a year compared with two for $P$. mesembryanthemi. Undoubtedly, this has slowed its rate of range expansion. Pulvinaria delottoi may experience higher mortality at its more basal feeding sites since older iceplant foliage is often overgrown and smothered by the surrounding iceplant canopy. Basal leaves commonly yellow and wither and, unless immature scales are able to abandon their feeding sites and secure others, they die. Hill (1980) reported that the coccid, Icerya seychellarum avoids mortality from leaf fall by migrating to adjacent leaves. While immature iceplant scales can move and change feeding sites, we frequently observed dead and dying scales on declining plant tissues at the bases of shoots; this suggested that death of plant tissues may be a significant mortality factor for $P$. delotto $i$ under natural conditions. Additionally, since the generation time of $P$. delotto $i$ is approximately double that of $P$. mesembryanthemi, mortality from natural enemies and other factors may be higher because exposure time is longer.

Pulvinariella mesembryanthemi and $P$. delottoi, while similar morphologically, show distinct biological differences in their phenology and their utilization of hosts in the genus Carpobrotus. Tests on settling ability and preference clearly demonstrate that settlers of $P$. delottoi are better able to utilize mature foliage as feeding sites. Neither species showed high settling success on iceplant stems. Selection and establishment of feeding sites for sap-feeding insects are influenced by both physical and nutritional characteristics of the host. For example, Newberry (1980) discovered that secretion of salt by the mangrove, Avicennia marina, was an effective barrier against settling of Icerya seychellarum crawlers. In nutritional studies, McClure (1980) found that two armored scales, Fiornia externa and Tsugaspidiotus tsugae, preferred settling on young pine needles with higher nitrogen concentrations. We did not investigate all possible factors, but because we found no difference in the mean stylet length of crawlers of the two scales, we can conclude that the lower success rates of $P$. mesembryanthemi on mature leaves is not based on stylet limitation. Similarly, the tougher epidermis of mature leaves did not prevent stylet penetration by either species. It is unlikely that crawlers are selecting settling sites on the basis of nitrogen concentration, since the concentration of soluble proteins and amino acids does not correlate with leaf age (Washburn, Grace, and Frankie, in preparation). The mature leaves of 
Carpobrotus typically contain high concentrations of phenolic compounds (personal observation), and $P$. delotto $i$ crawlers may have better physiological means of dealing with these potentially antibiotic constituents than $P$. mesembryanthem $i$ crawlers. In conclusion, further studies are necessary to establish why the crawlers of the two iceplant scales exhibit different settling preferences and abilities.

In California, the primary economic impact of iceplant scales will be realized on aizoaceous species and hybrids in the genus Carpobrotus because they are the dominant cultivars in the state. Species in the genus Dudleya are the major native hosts threatened by the scales' feeding activities. In southern California about a dozen aizoaceous species are utilized by CALTRANS as ground covers along highways. These species have not been colonized by $P$. mesembryanthemi, although our laboratory tests indicate that some are suitable for scale development. Host-plant range tests for $P$. delotto $i$ are incomplete, but this species has already colonized Lamprantbus and Crassula species at field sites in Alameda and Contra Costa counties. In our laboratory tests we were unable to successfully colonize Lampranthus glaucus and L. aurantiacus with $P$. mesembryantbemi crawlers. We did, however, successfully infest the same individuals of $L$. glaucus with $P$. delottoi crawlers, suggesting that host-range differences do exist between the two scale species.

Iceplant scales are well established in California and represent a potential threat to a wide range of introduced ornamentals in the Aizoaceae and Crassulaceae. The scales cause decline or death of their host plants through their destructive feeding which apparently saps the plants of essential nutrients. Additional damage is caused by the growth of sooty mold on honeydew exudates, which fouls photosynthetic processes. Damage to ornamental landscapes has been extensive, in part because iceplants are often cultured under inadequate water and fertilizer regimes (Farmer 1969). Plants growing along roadways are often stressed by pollution from automobile exhaust (Webb and Moran 1978), and there is generally a reduction in natural enemies like microbial control agents in these environments (Pinnock, Brand, and Milstead 1971). The accidental introduction of iceplant scales has placed an added stress onto ground covers already growing under suboptimal conditions, and in the absence of parasites from their native lands, iceplant scales have successfully spread throughout the state. Control and management of these scale pests can be affected by using biological control agents (Tassan, Hagen, and Cassidy 1983) and modifying cultural practices so that the impact on the hostplants is reduced. Several native parasites of iceplant scales are successfully established in many areas of California, and the activities of these insects have greatly reduced scale damage. 


\section{LITERATURE CITED}

AUCLAIR, J. L.

1963. Aphid feeding and nutrition. Ann. Rev. Entomol. 8:439-90.

BEARDSLEY J. W., and R. H. GONZALEZ

1975. The biology and ecology of armored scales. Ann. Rev. Entomol. 20:47-73.

BENNASSAY, C.

1961. Contribution a l'etude de l'influence de quelques facteurs ecologiques sur la limitation des pullulations de cochenilles-dispines. Inst. Nat. Rech. Agr. Ser. A. No. 3747.165 pp.

BLACKMORE, S.

1981. Penetration of the host plant tissue by the stylets of the coccid Icerya seychellarum (Coccoidea: Margaroidea) on Aldabra Atoll, Indian Ocean. Atoll Res. Bull. 254:33-38.

BORCHSENIUS N. S.

1953. New genera and species of scale insects of the family Coccidae (Homoptera: Coccoidea). (In Russian) Entomol. Obozr. 33:281-90.

BRAIN, C. K.

1920. The Coccidae of South Africa. V. Bull. Entomol. Res. 11:41 pp.

BROWN, C. E.

1958. Dispersal of the pine needle scale, Phenacaspis pinifoliae (Fitch). Can. Entomol. 90:658-90.

COLLINGE, W. E.

1911. On the locomotion and length of life of the young of Pulvinaria vitis var. ribesiae. Sign. J. Econ. Biol. 6:139-42.

COLLINS, L., and J. K. SCOTT

1982. Interaction of ants, predators, and the scale insect, Pulvinariella mesembryanthemi, on Carpobrotus edulis, an exotic plant naturalized in Australia. Aust. Entomol. Mag. 8:73-78.

CORNWELL, P. B.

1960. Movements of the vectors of the virus diseases of cacao in Ghana. II. Wind movements and aerial dispersal. Bull. Entomol. Res. 51:175-200.

DeLOTTO, G.

1967. The soft scale insects of South Africa. South Afr. J. Sci. 10:793-95.

1979. The soft scales (Homoptera: Coccidae) of South Africa, IV. J. Entomol. Soc. Afr. 42:245-56.

DONALDSON, D. R., W. S. MOORE, C. S. KOEHLER, and J. L. JOOS

1978. Scales threaten iceplant in Bay area. Cal. Agr. 32(10):4-7.

DOUGLAS, J. W.

1887. Note on some British Coccidae (No. 7). Entomol. Mon. Mag. 24:21-28.

FARMER, L. J.

1969. The pathology of ice plant used in highway landscaping. Unpublished report to the California Department of Transportation. 8 pp.

FLANDERS, S. E.

1970. Observations on host plant induced behavior of scale insects and their endoparasites. Can. Entomol. 102:913-26.

GILL, R. J.

1979. A new species of Pulvinaria Targioni-Tozzetti (Homoptera: Coccidae) attacking ice plant in California. Pan-Pac Ent. 55:241-50.

HALL, W. J.

1922. Observations on the Coccidae of Egypt. Technical and Scientific Service Bull. No. 22. Ministry of Agriculture, Government Press, Cairo. 57 pp.

HERIOT, A. D.

1934. The renewal and replacement of the stylets of sucking insects during each stadium, and the method of penetration. Can. J. Res. 11:602-12.

HILL, M. G.

1980. Susceptibility of Scaevola taccada (Gaertn.) Roxb. bushes to attack by the coccid Icerya seychellarum Westwood: the effects of leaf loss. Ecol. Entomol. 5:345-52.

HODGSON, C. J.

1967. Some Pulvinaria species (Homoptera: Coccidae) from the Ethiopian region. J. Entomol. Soc. South Afr. 30:198-211.

1968. Further notes on the genus Pulvinaria Targ. (Homoptera: Coccoidea) from the Ethiopian region. J. Entomol. Soc. South Afr. 31:141-74.

\section{MCCLURE, M. S.}

1976. Colonization and establishment of the red pine scale, Matsucoccus resinosae (Homoptera: Margarodidae), in a Connecticut plantation. Environ. Entomol. 5:943-47.

1980. Competition between exotic species: scale insects on hemlock. Ecology 61:1391-401. 


\section{MCLAREN, I. W.}

1971. A comparison of the population growth potential in California red scale, Aonidiella aurantii (Maskell), and yellow scale, A. citrina (Coquillet), on citrus. Aust. J. Zool. 19:189-204.

MILNE, W. M.

1981. Insecticidal vs. natural control of white wax scale (Gascardia destructor) at Kenthurst, New South Wales, Australia during 1972-1973. J. Aust. Entomol. Soc. 20:167-70.

MOORE, W. S., C. S. KOEHLER, J. L. JOOS, D. R. DONALDSON, D. V. CASSIDY, and R. J. GILL

1979. Ice plant scale insects. Coop. Ext. Leaflet 21084, University of California. 7 pp.

NEUNSCHWANDER, P., and M. PARASKAKIS

1980. Distribution and population dynamics of Saissetia oleae (Homoptera: Coccidae) within the canopy of the olive tree. Z. Angew. Entomol. 90:366-78.

NEWBERRY, D. McC.

1980. Infestation of the coccid, Icerya seychellarum (Westw.), on the mangrove Avicennia marina (Forsk.) Vierh. on Aldabra Atoll with special reference to tree age. Oecologia (Berl.) 45:325-30.

NUR, U.

1963. Meiotic parthenogenesis and heterochromatization in a soft scale, Pulvinaria bydrangeae (Coccoidea: Homoptera). Chrom. (Berl.) 14:123-39.

1972. Diploid arrhenotoky and automictic thelytoky in soft scale insects (Lecaniidae: Coccoidea: Homoptera). Chrom. (Berl.) 39:381-401.

1980. Evolution of unusual chromosome systems in scale insects (Coccoidea: Homoptera), pp. 97-117. In Insect Cytogenetics, Symposia of the Royal Entomol. Soc. of London 10, R. L. Blackman, G. M. Hewitt, and M. Ashburner, eds. Blackwell Scientific Publications, Oxford.

ODA, T.

1963. Studies on the dispersion of the mulberry scale Pseudaulacaspis pentagona. (In Japanese, English summary) Jap. J. Ecol. 13:41-46.

PESSON, P.

1941. Description du male de Pulvinaria mesembryanthemi Vallot et observations biologiques sur cette espece. (Hemiptera: Coccidae). Ann. Soc. Entomol. France. 110:71-77

PINNOCK, D. E., R. J. BRAND, and J. E. MILSTEAD

1971. The field persistence of Bacillus thuringiensis spores. J. of Invert. Path. 18:405-11.

PODDER, H. I., R. BAR-ZACAY, and D. ROSEN

1979. Population dynamics of the Mediterranean black scale, Sassetia oleae (Olivier), on citrus in Israel. 1. A partial life table. J. Entomol. Soc. South Afr. 42:257-66.

QUAYLE, H. J.

1911. Locomotion of certain young scale insects. J. Econ. Entomol. 4:301-06.

1916. Dispersion of scale insects by the wind. J. Econ. Entomol. 9:486-92.

QUINTANA, F. J.

1956. Pulvinaria mesembryanthemi (Vallot), (Homoptera: Sternorrhyncha) nueva cochinilla para la fauna Argentina y sus zooparasitos. LaPlata Univ. Nac., Facultad de Agron. Rev. 32 (1):75-110.

SCHULTZ, P. B.

1980. Delayed hatching of Japanese wax scale, Ceroplastes ceriferus (Homoptera: Coccidae) in locations strongly affected by marine winds. J. N.Y. Entomol. Soc. 88:70-71.

SOUTHWOOD, T. R. E.

1962. Migration of terrestrial arthropods in relation to habitat. Biol. Rev. 37:171-214.

STEPHENS, G. R., and D. E. AYLOR

1978. Aerial dispersal of red pine scale, Matsucoccus resinosae (Homoptera: Margarodidae). Environ. Entomol. 7:556-63.

STOETZEL, M. B., and J. A. DAVIDSON

1973. Life history variations of the obscure scale on pin oak and white oak in Maryland. Ann. Entomol. Soc. Am. 66:308-11.

TASSAN, R. L., K. S. HAGEN, and D. V. CASSIDY

1983. Imported natural enemies established against ice plant scales in California. Cal. Agr. 36(9-10):16-17. VALLOT, J. N.

1829. Nouvelle especes de Cochenilles. Acad. des Sci., Arts et Belles Lettres de Dijon, Compt. Rend. (1828-1829):30-33.

WASHBURN, J. O., and G. W. FRANKIE

1981. Dispersal of a scale insect, Pulvinariella mesembryanthemi (Homoptera: Coccoidea), on iceplant in California. Environ. Entomol. 10:724-27

WASHBURN, J. O., and L. WASHBURN

1984. Active aerial dispersal of minute wingless arthropods: exploitation of boundary layer velocity gradients. Science 223:1088-89.

WEBB, J., and V. C. MORAN

1978. The influence of the host plant on the population dynamics of Acizzia russellae (Homoptera: Psyllidae). Ecol. Entomol. 3:313-21.

WILLARD, J. R.

1976. Dispersal of California red scale (Aonidiella aurantii (Maskell)) (Homoptera: Diaspididae) in relation to weather variables. J. Aus. Entomol. Soc. 15:395-404 


\section{ACKNOWLEDGMENTS}

We wish to thank Eric Bellis, Marion Buegler, Jack Fraser, Ken Grace, Cathie Magowan, and Shelly Mandel for technical assistance. Richard Tassan and Jane Wright provided scale colonies, suggestions, and advice at various times during the research endeavour. Herbert Baker, Irene Baker, Rob Colwell, and Ken Hagen made helpful comments on an earlier draft of this report. Ray Gill kindly provided historical information, county records, references on iceplant scales, and comments on the manuscript. Irene Baker provided many hours of discussion which helped in examining scale-feeding behavior. To all of these individuals we are very grateful. Specimens of potential host plants were provided by the UC Botanical Garden. Funds for this research were provided by grants from the California Department of Transportation (CALTRANS), G. W. Frankie, principal investigator, and we gratefully acknowledge the support and encouragement of Dan Cassidy of that organization.

The contents of this report reflect the views of the authors who are responsible for the facts and the accuracy of the data presented. The contents do not necessarily reflect the official views or policies of the state of California or of the Federal Highway Administration. The report does not constitute a standard, specification, or regulation. 
The University of California in compliance with the Civil Rights Act of 1964, Title IX of the Education Amendments of 1972 , and the Rehabilitation Act of 1973 does not discriminate on the basis of race, creed, religion, color, national origin, sex, or mental or physical handicap in any of its programs or activities, or with respect to any of its employment policies, practices, $c$ procedures. The University of California does not discriminate on the basis of age, ancestry, sexual orientation, marital status, citizenship, nor because individuals are disabled or Vietnam era veterans. Inquiries regarding this policy may be directed to the Affirmative Action Officer, Division of Agriculture and Natural Resources, 2120 University Ave., University of California, Berkeley, California 94720 (415) 644-4270.

\section{$2.5 \mathrm{~m}-\mathrm{pr}-6 / 85-\mathrm{HS} / \mathrm{PF}$}

